\title{
COMMUNICATIONS
}

\section{DIAGNOSIS AND MANAGEMENT OF PARALYSIS OF THE EXTRINSIC OCULAR MUSCLES * WITH SPECIAL REFERENCE TO SURGICAL TREATMENT IN 219 CASES.}

BY

\section{T. KEITH LYLE AND ALEX. G. CROSS \\ London}

Although valuable contributions to the diagnosis and treatment of cases of ocular palsy, especially those of congenital origin, have been made by Duane (1916) and Posey (1916), and special methods of investigation of ocular paralysis have been described by Maddox (1907) and Landolt and Landolt (1913), it was not until much later that a comprehensive presentation of the subject was made by Bielschowsky $(1935,1938,1940)$, but even then advice as to surgical treatment was scanty.

The pioneer work of Chavasse (1939) has led, during the past 10 years, to a more complete understanding of paralytic squint, and standard principles of diagnosis and treatment have been accepted throughout the world. Chavasse was the first British writer to stress the importance of detailed diagnostic investigation in all cases of ocular deviation.

Treatises on the subject have been recently written by Krimsky (1948), Soriano and Garcia Nocito (1948), Fecosi (1948), and Lyle (1950). Detailed descriptions of the management of vertical muscle imbalance have been published by Epstein (1947), Anderson (1947), Burian (1950a, b), Dunnington (1948), Adler (1948), and McGillivray. (1948). The treatment of diplopia due to ocular muscle palsy has been studied by Lyle $(1941,1948,1949)$ and Neely (1947), and Anderson (1947) emphasizes the importance of detailed examination of the diplopia. Congenital oculomotor palsy affects the superior rectus more frequently than any other muscle, because of the relatively late embryonic cleavage of this muscle (Cross, 1944; Epstein, 1947). Traumatic cases also show that the superior rectus muscle is most usually affected (Cross, 1945). Zavalia (1948) has indicated that congenital paresis of the inferior oblique muscle is more commonly recognized at the present time than heretofore.

The surgical treatment of ocular palsy has been described by Anderson (1947), Payne (1948), and Dunnington (1948), and the technique of operations upon the oblique muscles has aroused

* Received for publication April 23, 1951. 
particular interest. Loutfallah (1949) reported that graduated myotomy of the inferior oblique at its insertion gives $10^{\circ}$ of correction, and that partial myectomy gives $6^{\circ}$ of correction. Satisfactory results of surgical treatment upon the oblique muscles have been described by Meesmann (1948), Franceschetti and Blum (1950), and Lloyd (1949). Recession of the inferior oblique at its insertion, in preference to partial myectomy of the muscle, is advised by Dunnington (1948), Lloyd (1949), and Payne (1948). Resection of the inferior rectus at its insertion and tucking of the superior oblique in paresis of these muscles is recommended by McGuire (1948) and McLean (1948).

Paralysis or paresis of one or more of the extrinsic ocular muscles can occur as a result of many different pathological lesions. Successful treatment demands investigation of the cause, accurate measurement of the amount of deviation of the visual axes, and careful assessment of the state of the binocular vision. Total paralysis of one or more of the extrinsic ocular muscles presents a complicated therapeutic problem, but even in such cases, much can be accomplished by means of operations designed:

(a) to limit the action of the synergic muscle or muscles of the unaffected eye;

(b) to overcome the contracture of the direct antagonists of the affected muscles;

(c) to increase the action of the affected muscle or muscles, sometimes by means of muscle-grafting operations;

$(d)$ to increase the action of the contralateral antagonists.

The more common finding in which the paralysis is incomplete, makes the prognosis much better and the treatment simpler, and in such cases it is possible, almost without exception, to restore a large field of binocular single vision as a result of adequate treatment.

Suppression of the vision of the deviating eye should only be allowed to occur in exceptional cases, and the use of occlusion of one eye, except as a temporary measure, is an admission of failure.

Many cases suitable for surgical treatment are of traumatic origin. The recent war provided much clinical material, and the routine ophthalmic examination of air crew candidates for the R.A.F. revealed a large number of hitherto undetected cases of ocular muscle imbalance due to congenital palsy of one or more of the extrinsic ocular muscles. Many of these cases, in which symptoms were already occurring, were amenable to surgical treatment. In compensated cases, where the deviation exceeded the limits allowed for air crew duties, operations enabled the men to reach the necessary medical standard. Other cases of ocular muscle palsy which respond well to surgical treatment are those due to exophthalmic ophthalmoplegia, to neuritis of the oculomotor nerves, and certain others of 
obscure pathology-provided that in each case the organic disease that caused the condition is no longer active.

\section{MATERIAL}

This paper is based on the study of 219 cases of palsy of one or more of the extrinsic ocular muscles which have been treated by operation and in which a satisfactory "binocular" result has been obtained. It is concerned with the clinical diagnosis of the affected muscle or muscles, with the aetiological cause of the palsy, and with the measurement of the degree of deviation in the primary position and in the different cardinal directions of gaze. It is also concerned with the state of the binocular functions, the estimation of the compensation of the deviation, and the treatment of the condition. With the exception of those cases due to active organic disease and those in which the lesion is gross, such as complete palsy of the 3rd cerebral nerve or severe orbital damage, the symptoms can largely be overcome by surgical treatment. The ages of the 219 patients ranged from 10 to 61 years. The aetiology of the 219 cases under review and the muscle or groups of muscles affected are tabulated below:

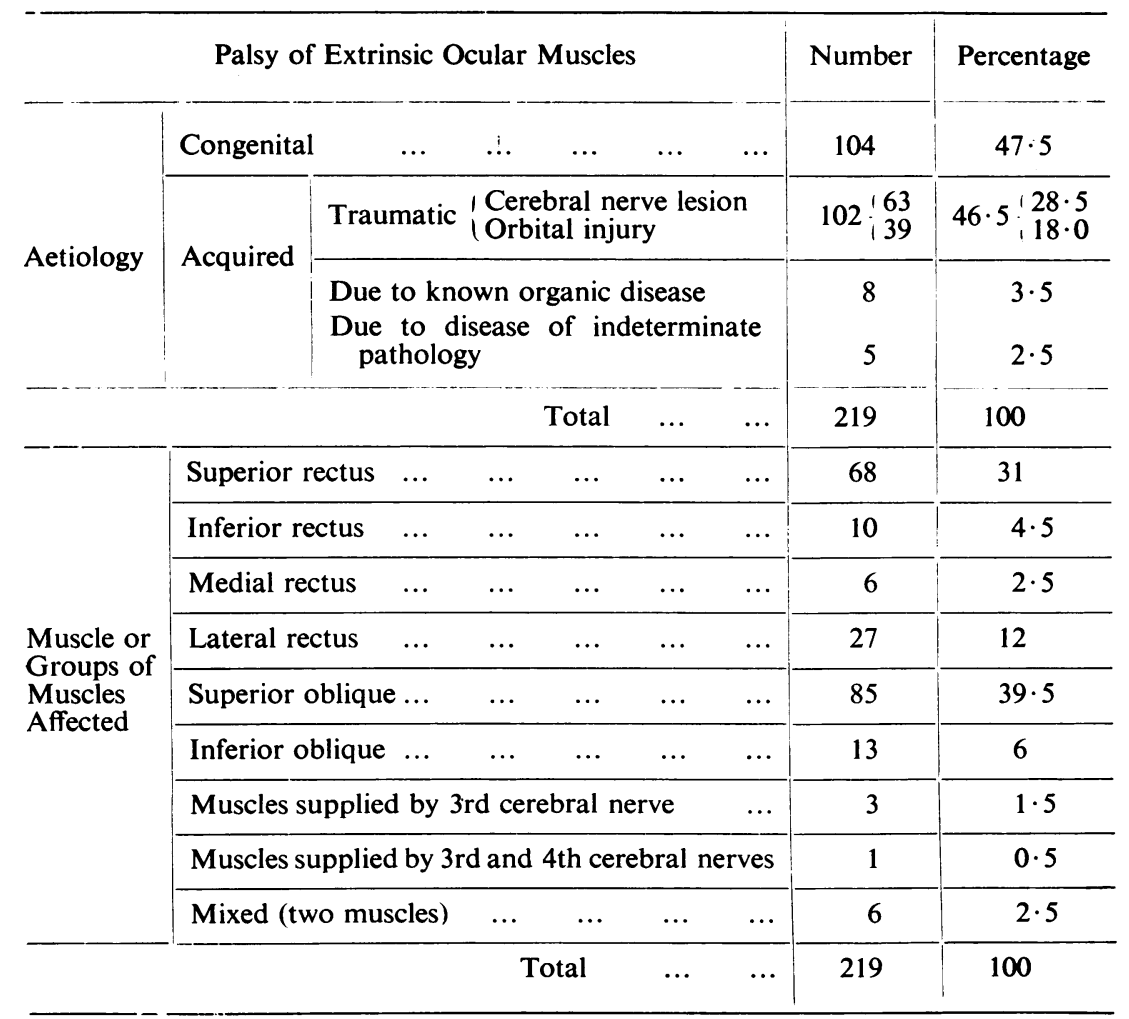




\section{Aetiology of Paralytic Strabismus}

(A) True Extrinsic Ocular Palsy due to a lesion of the nerve supplying the muscle, or of the muscle itself.

\section{(1) Lesions of Cerebral Nerve Supplying the Muscle}

(a) Conditions affecting the Motor Ne've Nuclei in the Mid-brain*.

(i) Congenital abnormalities, e.g. absence of the nerve nucleus (the condition sometimes affects the 6 th nerve nucleus).

(ii) Inflammation, e.g. encephalitis, neuro-syphilis, disseminated sclerosis.

(iii) Toxic causes, e.g. alcohol, carbon monoxide.

(iv) Degeneration, e.g. chronic nuclear ophthalmoplegia.

(v) Neoplasms.

(b) Conditions affecting the Nerve Roots below the Nuclei, and the Nerve Trunks (fascicular).- The commoner causes are:

(i) Inflammation, e.g. encephalitis, neuro-syphilis, disseminated sclerosis.

(ii) Vascular causes, e.g. thrombosis, haemorrhage, embolism, aneurysm.

(iii) Neoplasms.

(c) Conditions affecting the Motor Nerve Trunks supplying the Muscle.

(i) Trauma (especially involving 4th and 6th nerves, and sometimes $3 \mathrm{rd}$ ), e.g. direct injury causing complete or partial transection of the nerve; a haematoma pressing upon the nerve or interfering with its blood supply; a stretching of the nerve due to cerebral oedema or intrac anial haemorrhage.

(ii) Inflammation, e.g. peripheral neuritis due to diabetes, herpes zoster, 'rheumatism'. meningitis (including localized meningitis due to extension from petrousitis which may cause 6th-nerve palsy).

(iii) Toxic causes, e.g. lead, alcohol.

(iv) Vascular causes, e.g. pressure upon a nerve by a thickened artery, or by a basal aneurysm.

\section{(2) Lesions of the Muscle Itself}

(a) Congenital Absence or Abnormal Insertion of a Muscle.

(b) Direct Trauma, causing one of the following:

(i) Haemorrhage into the substance of the muscle or into its sheath and causing subsequent fibrosis.

(ii) Damage to a muscle, sometimes with subsequent fibrosis, e.g. as a complication of an operation on the eyeball or its adnexae.

(iii) Damage to the attachments of a muscle, e.g. damage to the origin of the inferior oblique (as may occur in orbital injury) or damage to the pulley of the superior oblique (as may occur in operation upon the ethmoid or frontal sinuses or due to head injury).

(c) Myopathy or Myositis, e.g. myasthenia gravis, exophthalmic ophthalmoplegia, thyrotoxic myopathy, chronic ocular myopathy.

* Lesions affectin , the nerve nucleus usually affect several muscles, on account of the proximity of the 3 rd and $4:$ h nuclei a id it e interccmmunication of the nuclei by transverse and longitudinal fibres. 
(B) 'Relative' Ocular Palsy due to a lesion of the bony orbit as a result of which there is a deviation of the visual axis.* This may be caused by:

(a) injury causing damage to the supports of the eyeball;

(b) injury causing loss of orbital fat such as may be produced by a fracture of the floor of the orbit. This may cause enophthalmos and a convergent deviation;

(c) a space-occupying lesion of the orbit, or adjacent to it, e.g. haemorrhage, inflammation, neoplasm, thyrotoxicosis. Such a lesion may cause direct exophthalmos, which may give rise to a divergent deviation or, depending upon its site, to a displacement of the eyeball upwards, downwards, inwards, or outwards.

\section{ANATOMY}

The general anatomy of the extra-ocular muscles has been fully described, and their mode of action is well understood (Figs 1 and 2, and Table A). In the surgical treatment of these muscles, however, it is important to emphasize the fact that the superior and inferior

TABLE A

ACTIONS OF THE EXTRINSIC OCULAR MUSCLES

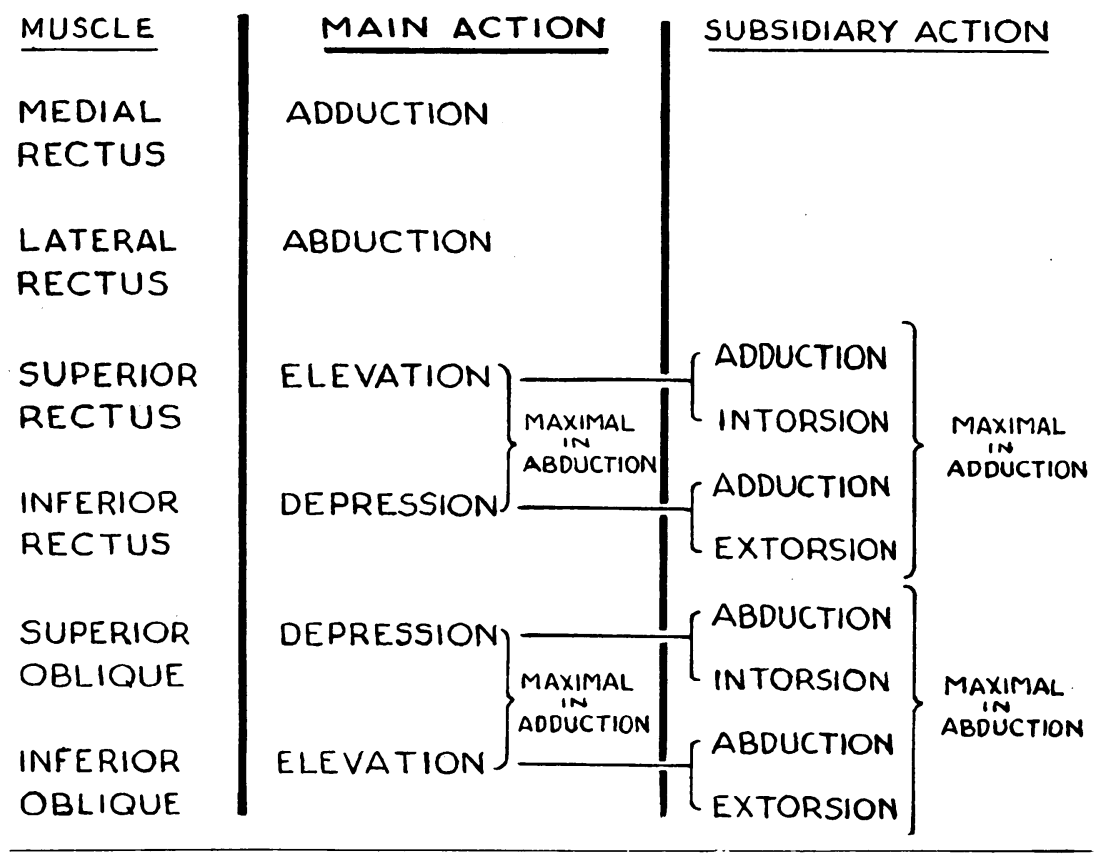

* Severe orbital injury may occur, even to the extent of grossly displacing the eyeball as a whole, without causing deviation of the visual axis, and gross deviation of the visual axis may occur without displacement of the eyeball as a whole. 


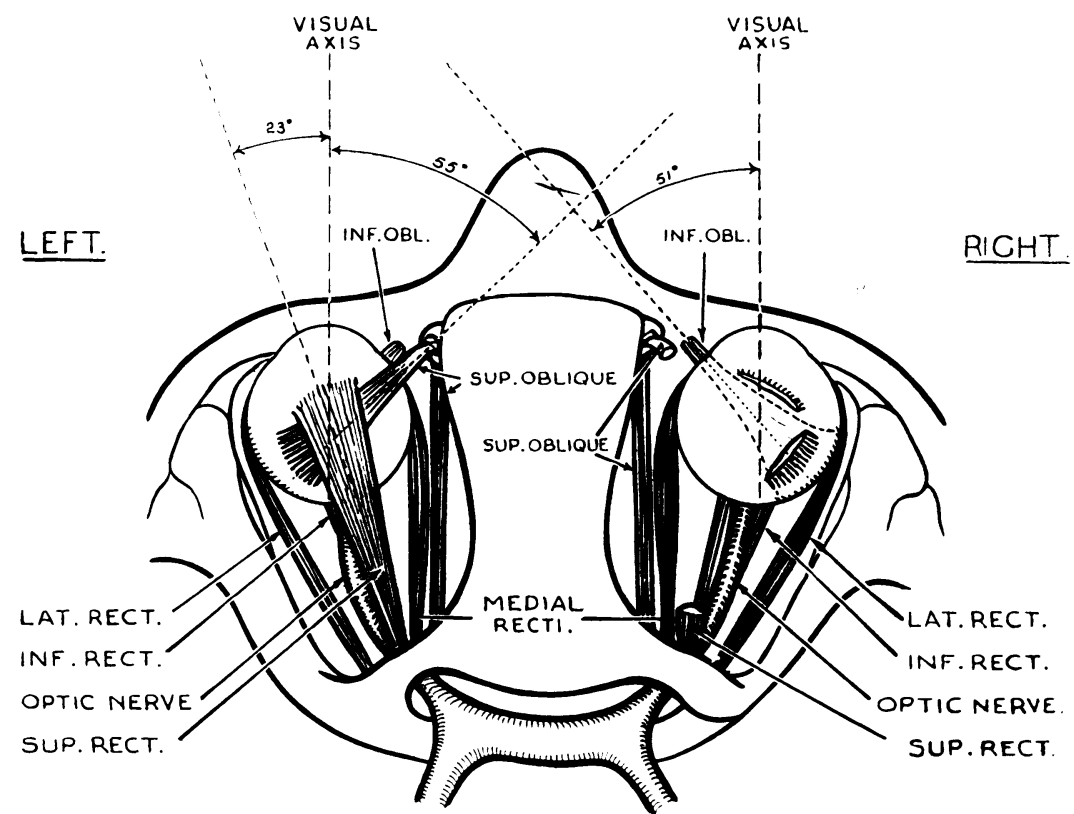

FIG. 1.-Position of extrinsic ocular muscles.
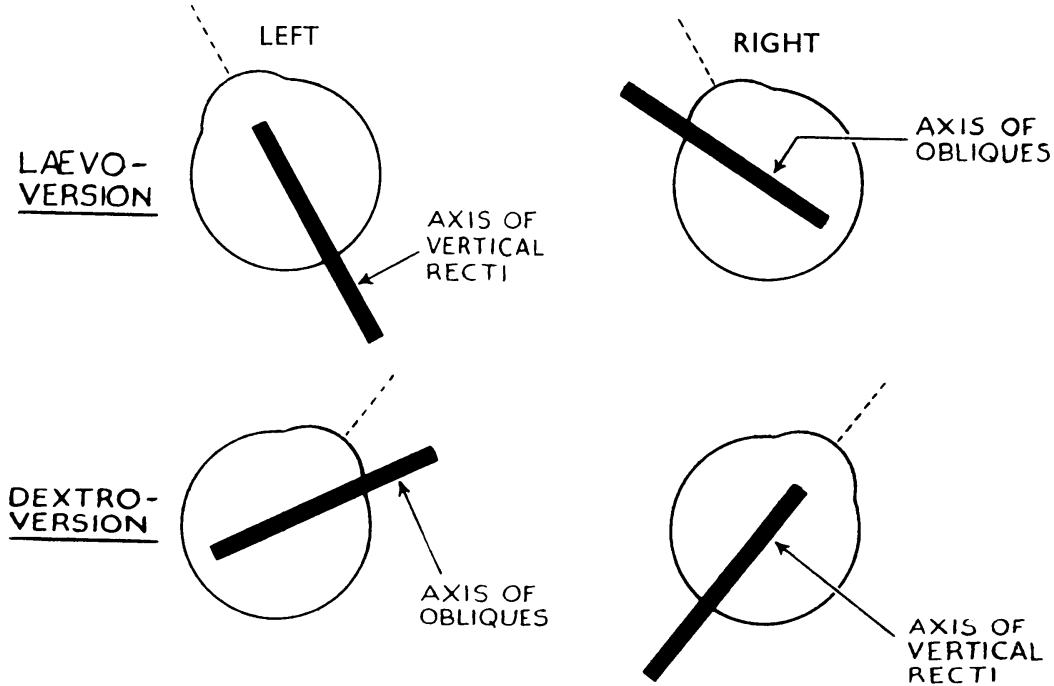

FIG. 2.-Diagrams to show how on latero-version the vertical recti of one eye and the obliques of the other eye approach parallelism and act synergically.

rectus muscles exert their maximal vertical action in abduction, while the oblique muscles exert their maximal vertical action in full 
adduction. The medial and lateral recti, which exert only a primary action on the globe, exert this with the eye looking straight ahead, or when it is elevated or depressed. The two eyes work together and the muscles of the two eyes act synergically to move them in the same direction. Thus the superior rectus of one eye and the inferior oblique of the other, and the inferior rectus of one eye and the superior oblique of the other are synergic muscles, as are the lateral rectus of the one eye and the medial rectus of the other.

\section{Pathological Sequelae of an Extrinsic Ocular Muscle Palsy}

In all cases of extrinsic ocular muscle palsy, certain sequelae take place to a greater or lesser extent: to a greater extent if the cause of the palsy be a nerve lesion, to a lesser extent if the cause of the palsy be a local orbital injury or a disease primarily affecting the function of the muscle directly or indirectly.

These sequelae are:

(1) Overaction of the contralateral synergist.

(2) Contracture of the direct antagonist.

(3) Secondary palsy of the contralateral antagonist.

Thus, in a case of a right lateral rectus palsy, the sequelae are overaction of the left medial rectus, contracture of the right medial rectus, and secondary palsy of the left lateral rectus (Fig. 3, overleaf).

Similarly, in the case of a left superior oblique palsy, the sequelae are overaction of the right inferior rectus, contracture of the left inferior oblique, and secondary palsy of the right superior rectus (Fig. 4, overleaf).

These sequelae tend to progress in degree and to become more established the longer the palsy exists, so that eventually the paralytic features of the case tend to disappear and to be replaced by more or less concomitant characters. In some cases, the contracture of the direct antagonist of the affected muscle becomes progressively greater and causes the angle of deviation of the squint to become markedly increased.

Although paresis of one of the horizontally acting muscles may eventually give rise to a clinical condition almost indistinguishable superficially from a concomitant strabismus (convergent or divergent as the case may be), paresis of one of the vertically acting muscles usually gives rise to a vertical strabismus which is concomitant only when the eyes are in latero-version (laevo- or dextro- according to the muscle affected). Pure concomitant vertical strabismus is rare; it is invariably due to paresis of at least two vertically acting musclesone whose maximal vertical action is in dextro-version, and one whose maximal vertical action is in laevo-version. This may be due 


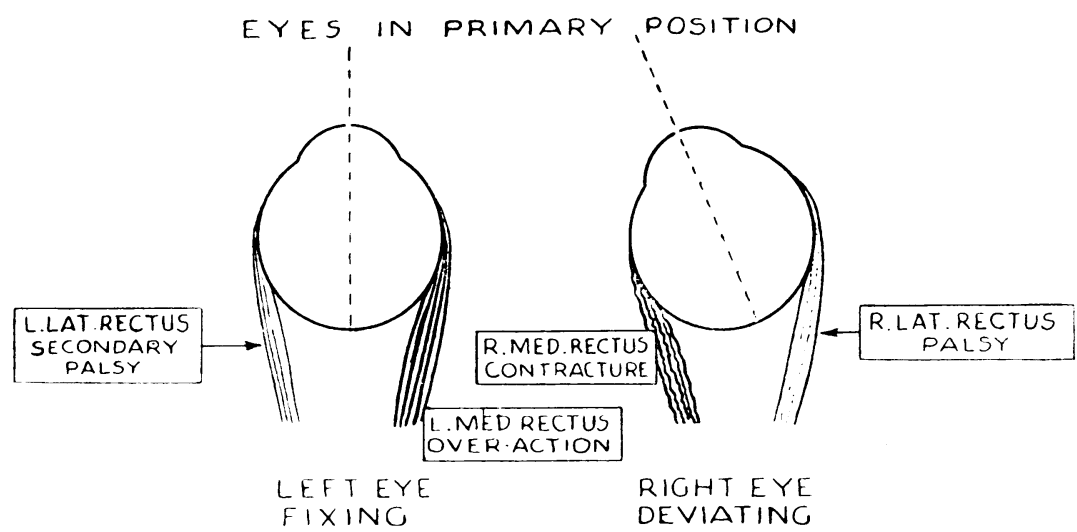

Fici 3. - Sequela of an extrinsic ocular muscle palsy. Paresis of right lateral rectus.

\section{EYES IN DEXTRO-VERSION}
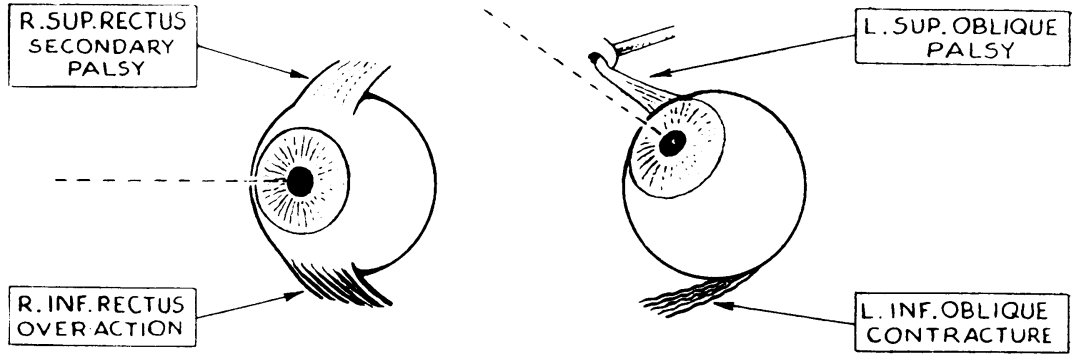

RIGHTEYE FIXING

\section{LEFT EYE DEVIATING}

Fic. 4. - Sequela of an extrinsic ocular muscle palsy. Paresis of left superior oblique.

to paresis of both elevators or of both depressors of one eye, or to paresis of a dextro-elevator of one eye and a laevo-depressor of the other or vice rersa.

\section{INVESTIGATION}

The elucidation of the history of onset of the symptoms and their course, together with adequate questioning regarding all possible aetiological factors, is an essential preliminary to the examination.

SyмртомS.--The chief symptoms are diplopia, loss of binocular vision, defective ocular movement, and compensatory head posture.

(i) Diplopia.-This is the common and universal symptom in cases of ocular palsy, except in those of congenital origin when it may be absent on account of compensation or because of uniocular suppression. It may occur in all directions of the gaze or only in certain directions. It may be constant or it may be ir.termittent. In rare instances diplopia may be 
absent in acquired ocular palsy (apart from those cases where one eye is bandaged or has lost its vision). Its absence is the result of suppression of the vision of one eye, which may occur rapidly after the onset of an ocular palsy in persons of defective intellectual capacity or of hysterical personality.

Useful information may be obtained by interrogating the patient regarding the type and behaviour of the diplopia. Enquiry as to whether the diplopia is "horizontal" or "vertical" reveals whether or not a vertically acting muscle is at fault, because, if the double vision is entirely horizontal, no vertically acting muscle can be affected. The nature of the onset of the diplopia gives helpful information, and it is important to know if it is constant or intermittent and whether it can be overcome by the adoption of a compensatory head posture.

In some cases of slight paresis, diplopia may occur only when looking in a certain direction of the gaze, or it may occur only when viewing distant objects or only when viewing near objects.

(ii) Loss of Binocular Vision without diplopia may be noticed in cases where a latent deviation gradually becomes manifest, as in certain cases of ocular palsy of congenital origin. The patient may notice that he is using only one eye at a time and may volunteer that he "finds himself closing one eye", especially when reading.

(iii) Defective Movement, or excessive movement of one eye as compared with the other in a particular direction of the gaze, may be noticed by the patient or by his relatives. Defective movement occurs in cases of congenital palsy of the lateral rectus muscle when the deficient abduction of the affected eye is obvious when the gaze is directed laterally to the ipsolateral side. Excessive movement occurs in cases of palsy of one of the vertically acting muscles when the eyes are directed into the appropriate position of latero-version, where the updrift (or downdrift) of the contralateral eye is obvious.

(iv) Compensatory Head Posture, adopted in the interests of binocular vision, especially in cases of congenital origin, may be the only abnormality noted by the patient or more usually by his relatives. Thus such patients are sometimes directed to an orthopaedic department with a diagnosis of torticollis due to contracture of the sterno-cleido-mastoid muscle, notwithstanding that no obvious contracture of this muscle exists. It is an interesting fact that an abnormal head posture may be unnoticed or ignored throughout childhood. Even in adult life a patient with a congenital palsy of a vertically acting extrinsic ocular muscle and an obvious compensatory head tilt may be quite unconscious of his abnormality, although photographs taken many years previously may show it to have been present throughout life.

A compensatory head posture may exhibit one or more of the following components:

(a) elevation or depression of the chin;

(b) turn of the face to one or other side;

(c) tilt or inclination of the head to one or other side. 
It may be stated as a general rule that, in a case of ocular palsy, the head is placed in such a position that the eyes become directed away from the direction of the main action of the affected muscle, or (what amounts to the same thing) "the face looks towards the false image".

Elevation or depression of the chin is commonly employed to overcome diplopia due to a vertical deviation of the visual axes. The chin is elevated if there is weakness of an elevator muscle, and depressed if there is weakness of a depressor muscle. Elevation or depression of the chin may also be employed to overcome diplopia due to a horizontal deviation of the visual axes; elevation of the chin helps to overcome divergence, and depression of the chin helps to overcome convergence.

Turning the face to the right or left helps to overcome diplopia due to a horizontal deviation of the visual axes, caused by weakness of one of the horizontally acting muscles.

Tilting of the head takes place as a compensatory mechanism in order to reduce the vertical deviation of the visual axes and/or to overcome cyclotropia. The latter may be due to the primary palsy or to one of its sequelae.

Clinical Examination.-This involves an examination of the head posture, ocular posture, ocular movements, and diplopia. It necessitates the use of the cover test, the Maddox rod, the Hess (or Lancaster) screen, and the synoptophore (or other form of major amblyoscope).

Deviation of the Visual Axes.-This is usually evident on inspection, especially if one of the horizontally acting muscles is affected.' In cases of paresis of one of the vertically acting muscles, the deviation may not be obvious, since there are two elevators and two depressors belonging to each eye. The patient may elect to fix with the paretic eye instead of the non-paretic eye, either because the former enjoys better vision, or because by so doing the separation of the images is greater and suppression occurs more readily, or because it is the hypotropic eye (looking down being a more useful ocular movement than looking up).

Limitation of Movement.-Limitation in the direction of main action of the paralysed muscle is often an important diagnostic feature, especially if accompanied by exaggeration of the corresponding movement of the other eye. It is less noticeable in paralysis of the vertical recti, and least noticeable in paralysis of the oblique muscles, but it is usually demonstrable if the ocular movements are carefully tested in all directions of the gaze and the excursions of the two eyes compared. The limits of ocular movement depend not only on the action of the eye muscles but also upon the fascial check ligaments.

A maximal innervation is not necessary in order that the eyes shall reach the normal limits of movement, therefore a paretic muscle may be capable of bringing the eye to the normal limit of movement by excessive innervation.

Study of the Diplopia.- - This is one of the easiest methods of determining the muscle or muscles affected. It depends upon the two cardinal facts that the separation of the two images is maximal in the direction of main action 
of the paralysed muscle, and that the image of the affected eye is projected into space in the direction of action of the paralysed muscle. Estimations of the direction of gaze in which the separation of the images is maximal, and of the eye to which the "further-away" image belongs, lead directly to the diagnosis. Fig. 5 shows diagrammatically the main muscles concerned in the various diagnostic positions of the gaze. The diagnosis is more complicated if two or more muscles are affected, but the paretic ones can usually be satisfactorily identified.

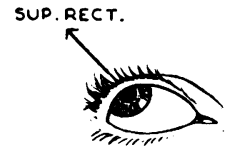

DEXTRO-ELEVATION

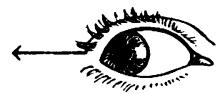

LAT RECT.

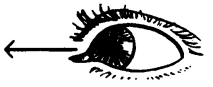

MEO.RECT.

DEXTRO-VERSION

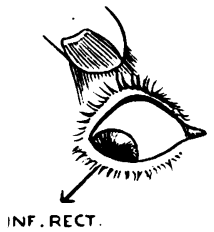

DEXTRO-DEPRESSION
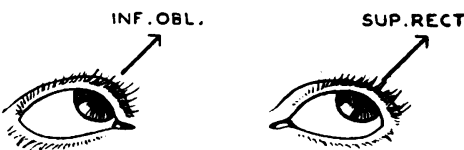

LEVO-ELEVATION
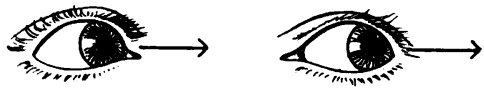

MED.RECT LEVO-VERSION
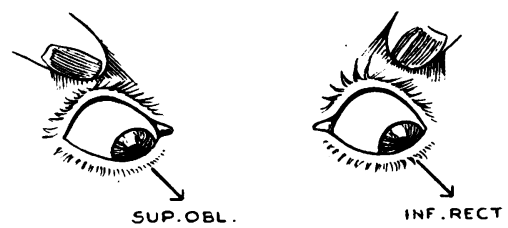

LFVO-DEPRESSION

FIG. 5.-The six diagnostic positions of the gaze.

The use of a bar of light instead of a spotlight in studying the diplopia in the various directions of the gaze gives additional diagnostic information with regard to torsion. Fig. 6 (overleaf) shows the extent and nature of the diplopia in typical cases of palsy of the individual extrinsic ocular muscles of the left eye.

Cover Test.-This should be performed for fixation at a distance as well as for near fixation; it gives reliable evidence of the presence or absence of binocular fixation and of the direction and extent of the ocular deviation. If binocular fixation is present, it also provides evidence of the presence or absence of latent deviation and of the rate of recovery of binocular fixation.

Estimation of the Angle of Deviation between the two visual axes is carried out with the Maddox rod and spotlight. This offers a suitable standard method of measurement which can be carried out either in the consulting room or at the bedside. If the test is repeated at intervals in identical circumstances, it is a suitable method by which spontaneous recovery may be assessed. We have used this measurement of the deviation of the eyes as a basis for planning the appropriate surgical treatment, 
LEFT MEDIAL RECTUS

LEFT LATERAL RECTUS
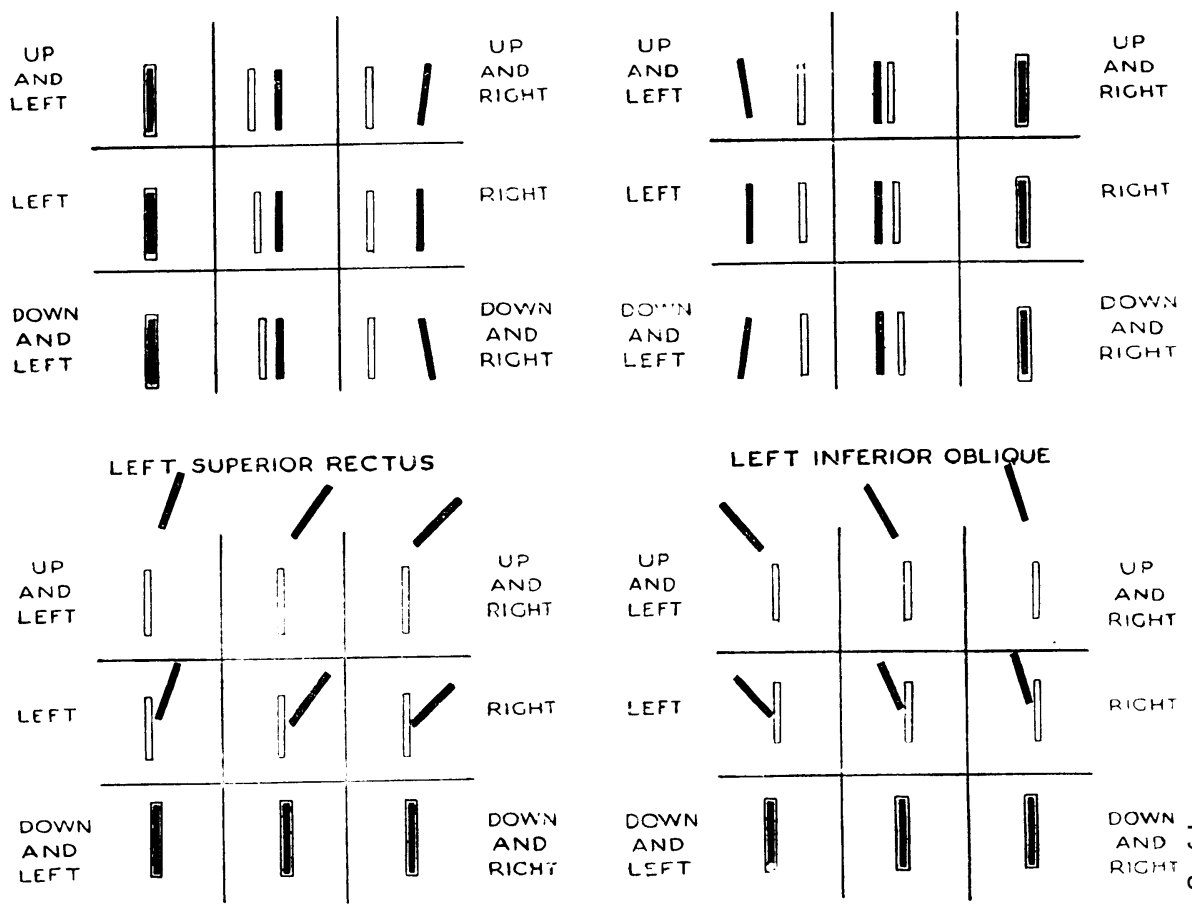
although the results of other tests must also be taken into consideration. The test should be carried out at a distance of $6 \mathrm{~m}$. from a spotlight, and the Maddox rod should be placed in front of each eye in turn, as the

UP

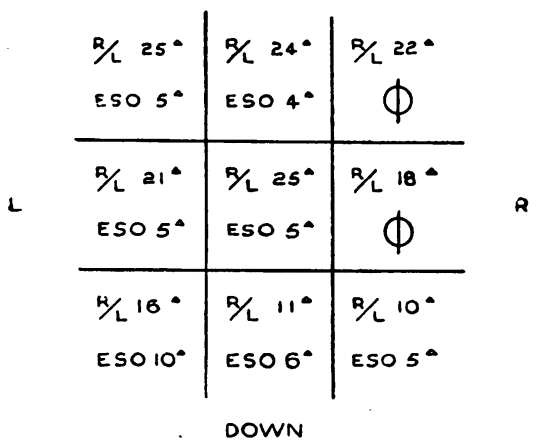

Fig. 7(a).-Maddox rod chart at $1 \mathrm{~m}$. before operation. Palsy of left superior rectus duc to orbital trauma.
UP

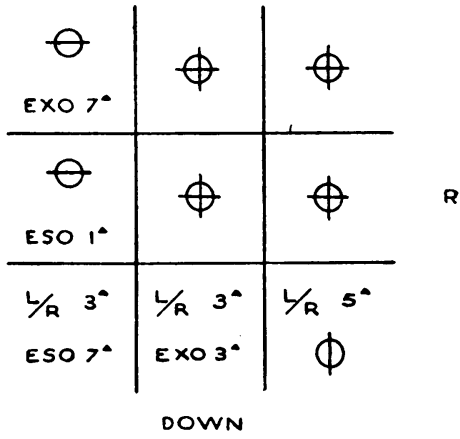

FIG. 7(b).-Maddox rod chart at $1 \mathrm{~m}$. after operation-resection of left superior rectus.

measurement may vary according to which is the fixing eye. The measurements are more accurate when the dis placement is neutralized by prisms than

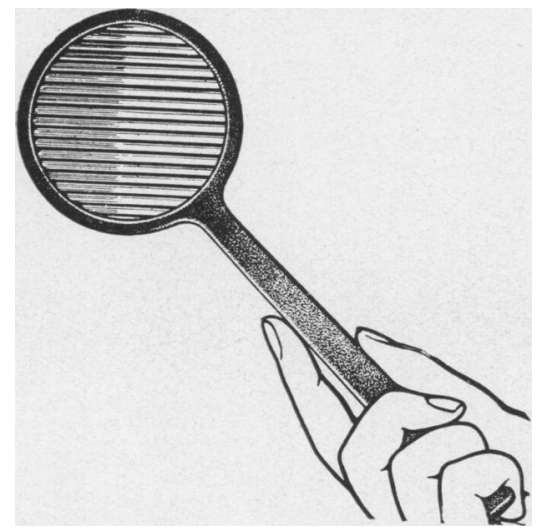

Fig. 8.- Large Maddox rod mounted on handle. when the tangent scale is employed and speed of examination is increased by the use of a prism bar. The Maddox rod and a movable spotlight held at a distance of one metre are used in most cases for measurement of the angle of deviation of the visual axes in the nine cardinal directions of the gaze. This gives valuable diagnostic information. An example of a pre- and post-operative Maddox rod chart is shown in Fig. 7 . To obtain the maximum amount of information from the test it should be carried out twice, first with tho Maddox rod in front of the right eye, and then with the Maddox rod in front of the left eye. It is advantageous to use a large Maddox rod mounted on a handle (Fig. 8) and two prism bars, one for measuring vertical deviations and one for horizontal deviations (Fig. 9, overleaf).

Hess Screen.-This has been used extensively in our work. It not only demonstrates the muscle or muscles primarily affected, but also indicates the sequelae of the initial palsy affecting other muscles. It also provides a diagrammatic record of the condition of the extrinsic ocular muscles at any one period, so that progression or retrogression of the deviation, and 


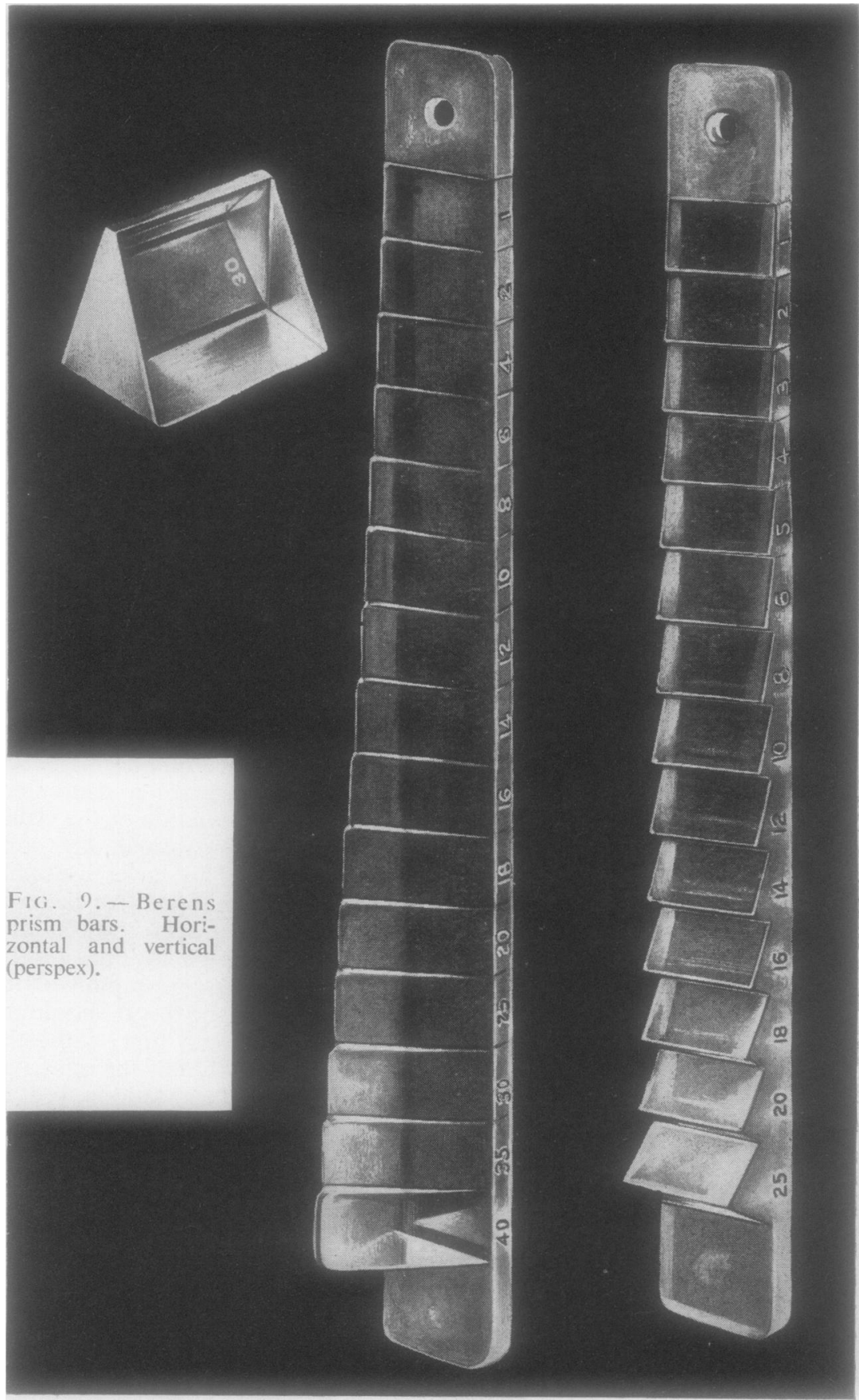


the results of surgical treatment, can be clearly estimated. The apparatus (Fig. 10) consists of a tangent screen and an indicator:

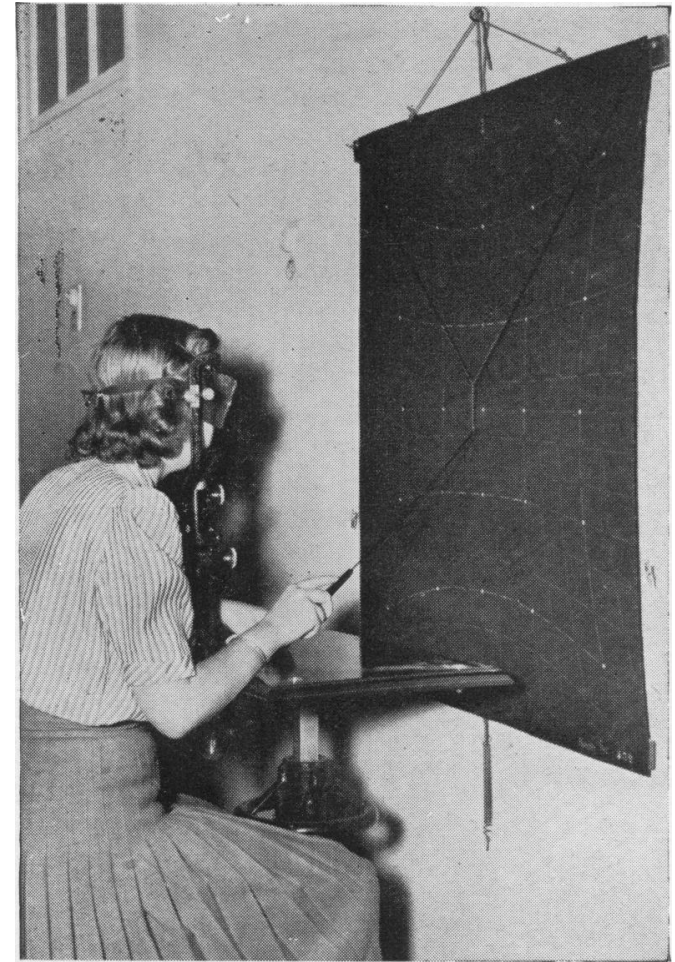

FIG. 10.-Hess screen.

Reproduced from " Worth and Chavasse's Squint ", ed. T. K. Lyle, 8th ed. 1950. (Baillière, Tindall, and Cox, London.) (i) Tangent Screen.-This is made of black cloth and is approximately one yard square. It is marked out by a series of red lines, which subtend an angle of $5^{\circ}$ between them. At the zero point situated at the middle of the screen, and at the points of intersection of the $15^{\circ}$ and $30^{\circ}$ lines with one another and with the horizontal and vertical lines, there is a red dot. These red dots form an "inner square" of nine dots and an "outer square" of sixteen dots. The dots forming the inner square are round, and those forming the outer square are rectangular.

(ii) Indicator.-This consists of three green cords of equal length knotted together to form a Y. The end of each green cord is connected to a black thread, one of which is attached to the tip of a movable black rod or pointer $50 \mathrm{~cm}$. long; the other two black
of the screen and are attached threads pass through loops situated at the upper corners of the screen and are attached to small weights which keep them taut.

This arrangement enables the patient holding the black rod to move the indicator over the surface of the screen in any direction, but (owing to the method of attachment of rod to indicator) the influence of muscle and joint sense in judging the position of the indicator is eliminated.*

The patient is seated $50 \mathrm{~cm}$. (the length of the rod) from the screen with his eyes level with, and opposite to, the zero point. He wears a pair of red and green glasses and takes the pointer in his right hand. It is important to see that the colour of the red and green glasses is complementary to that of the green cord and red dots respectively, and that the patient's eyes are on a level with the centre dot on the screen. A suitably placed head-rest mounted on a small table (Fig. 10) is a great advantage. The patient should be told that the red glass has been placed in front of his right eye and the green glass in front of his left eye. It should be

* The Law Indicator, consisting of a black rod with a green ring at its tip, is a simpler device but less accurate. 
demonstrated to him that when his left is covered he can see only the red dots on the screen, and that when his right eye is covered he can see only the green cord. He should then be told that he will be required, by moving the pointer, to place the knot at the centre of the three green cords upon each red dot in turn, beginning at the centre dot, passing to that immediately above it, and then proceeding in a clockwise direction until all the dots have been dealt with. The test is repeated with the red glass in front of the left eye and with the green glass in front of the right eye. The peripheral (rectangular) dots are usually only used if the degree of paresis is insufficient to show any obvious defect when the central (round) dots are used. If the colour of the glasses is not truly complementary to those of the screen and indicator cord, the patient may see two series of dots, one red and the other dark green, and the same remark may apply to the cords. This will jeopardize the result unless it is pointed out to the patient that he must concentrate on the bright red dots and the bright green cord, and ignore the others if they are visible. Sometimes suppression causes difficulty, but this may temporarily be overcome by covering the master eye for a few seconds immediately before taking a reading.

Examination of patients by means of the synoptophore (or other major amblyoscope) is of the greatest value. The most important information obtained relates to the state of the binocular vision, to the presence of suppression, and to the fusional duction power. The angle of deviation can be obtained, not only in the primary position but also in lateroversion, and also in some instruments (e.g. the Lyle major amblyoscope), in elevation and in depression.

Other EXAminations.-In addition to clinical examination, both ophthalmic and general, various ancillary examinations may be necessary to discover the aetiology of the condition. It may be that the case is clearly of congenital origin. On the other hand the cause may be indefinite, so that a general medical examination with special reference to the central nervous system is required including perimetry and scotometry. Examination of the urine, of the blood Wassermann reaction, and of the skull and orbits by radiological methods may be necessary. Lumbar puncture, and even encephalography, ventriculography, and arteriography may be essential in some cases.

It cannot, however, be overstressed that these laboratory and other ancillary methods of investigation should not be carried out until a detailed case history has been taken and a thorough clinical examination made. In many cases the cause of the ocular palsy is patently obvious if due attention is paid to the clinical facts.

Cases of compensated ocular palsy of congenital origin often show signs of decompensation in adult life, and may thus be misdiagnosed and thought to be cases of acquired palsy.

It is important from the point of view of treatment to differentiate between congenital and acquired ocular palsy, because whereas in the former the treatment is invariably operative, in the latter the treatment 
varies according to the cause. Furthermore, it may be important from the medico-legal point of view to know the exact cause of the condition.

It is, therefore, desirable to have a clear conception of the clinical features which distinguish the two types of case. These are set out in Table B.

TABLE B

DIFFERENTIAL DIAGNOSIS

\begin{tabular}{|c|c|c|c|}
\hline \multicolumn{2}{|l|}{ Ocular Palsy } & Congenital & Acquired \\
\hline \multicolumn{2}{|c|}{ Onset of Symptoms } & $\begin{array}{l}\text { Usually indefinite and inter- } \\
\text { mittent }\end{array}$ & Usually definite and sudden \\
\hline \multirow[b]{2}{*}{ Symptoms } & $\begin{array}{l}\text { Subjective } \\
\text { (patient's } \\
\text { own symp- } \\
\text { toms) }\end{array}$ & $\begin{array}{l}\text { (a) Intermittent diplopia, or } \\
\text { diplopia in certain directions } \\
\text { of the gaze } \\
\text { (b) Difficulty in focusing } \\
\text { (c) Preference for reading with } \\
\text { one eye closed } \\
N \text {.B.-If the condition is fully } \\
\text { compensated there are no sub- } \\
\text { jective symptoms. }\end{array}$ & $\begin{array}{l}\text { Diplopia almost invari- } \\
\text { ably present (depending } \\
\text { upon the severity of the } \\
\text { palsy this may occur in all, } \\
\text { or only in certain direc- } \\
\text { tions of the gaze) }\end{array}$ \\
\hline & $\begin{array}{l}\text { Objective } \\
\text { (observations } \\
\text { made by } \\
\text { relatives) }\end{array}$ & $\begin{array}{l}\text { (a) Intermittent squint, and/or } \\
\text { eyes "look crooked" in cer- } \\
\text { tain directions of the gaze (e.g. } \\
\text { updrift or downdrift of oppo- } \\
\text { site eye on latero-version) } \\
\text { (b) Abnormal head posture }\end{array}$ & $\begin{array}{l}\text { The squint is noticeable to } \\
\text { others if the angle of devia- } \\
\text { tion is sufficiently large. } \\
\text { The angle of deviation is } \\
\text { usually constant and not } \\
\text { intermittent }\end{array}$ \\
\hline \multirow{4}{*}{ Signs } & $\begin{array}{l}\text { Compensa- } \\
\text { tory Head } \\
\text { Posture }\end{array}$ & $\begin{array}{l}\text { Usually present, but the patient } \\
\text { is unaware of it, unless others } \\
\text { draw his attention to it } \\
\text { Accompanying the compen- } \\
\text { satory head posture there } \\
\text { is scoliosis with anatomical } \\
\text { changes in the vertebral } \\
\text { column }\end{array}$ & $\begin{array}{l}\text { May occur, but if so the } \\
\text { patient is usually aware of } \\
\text { it } \\
\text { No anatomical changes } \\
\text { present }\end{array}$ \\
\hline & $\begin{array}{l}\text { Angle of } \\
\text { Latent } \\
\text { Deviation }\end{array}$ & $\begin{array}{l}\text { This may be large and yet the } \\
\text { symptoms may be only slight }\end{array}$ & $\begin{array}{l}\text { This may be small and yet } \\
\text { the resulting symptoms } \\
\text { may be pronounced }\end{array}$ \\
\hline & $\begin{array}{l}\text { Angle of } \\
\text { Secondary } \\
\text { Deviation }\end{array}$ & $\begin{array}{l}\text { This is usually only slightly } \\
\text { greater than that of the } \\
\text { primary deviation, i.e. the } \\
\text { deviation tends to be con- } \\
\text { comitant }\end{array}$ & $\begin{array}{l}\text { This is usually much } \\
\text { greater than that of the } \\
\text { primary deviation, i.e. the } \\
\text { deviation tends to be in- } \\
\text { comitant }\end{array}$ \\
\hline & Suppression & $\begin{array}{l}\text { Suppression is always present } \\
\text { to some extent. It usually } \\
\text { affects one eye (but not neces- } \\
\text { sarily the one with the paretic } \\
\text { muscle) in the ocular posture } \\
\text { in which the affected muscle } \\
\text { has its main action }\end{array}$ & $\begin{array}{l}\text { Suppression is absent at } \\
\text { first but may occur later }\end{array}$ \\
\hline
\end{tabular}




\section{Surgical Treatment}

Surgical treatment is indicated in all cases of paralytic strabismus provided that the causative condition has become inactive and that diplopia persists. In the congenital type a considerable degree of suppression tends to mask diplopia and in many cases a compensatory head posture may overcome this symptom to a great extent. Paralytic strabismus due to head injury may undergo a large degree of spontaneous recovery and only about 10 per cent. of cases require surgical treatment. It is therefore essential to allow a reasonable period of time to elapse (at least 4 months), and/or to wait until the ocular deviation is static before surgical treatment is undertaken. On the other hand, in some cases, prophylactic surgical treatment may be considered. In all muscles throughout the body, paresis is followed by contracture of the antagonists. In the case of skeletal muscles, contracture may be prevented by the appropriate use of splints. Splinting of an eye with paresis of an extrinsic muscle, however, is not a practical proposition, but loosening of the direct antagonistic muscle by some surgical method may prevent its contracture and thus assist recovery of the paralysed muscle.

Pre-Operative Treatment.- It is of great assistance in achieving full success in surgical treatment if the binocular vision can be stimulated by orthoptic methods before operation. If the visual axes are made approximately parallel, a more rapid resumption of normal binocular activities will occur if the binocular functions have been kept exercised than if some degree of suppression has occurred. In some patients prisms may be prescribed temporarily to overcome diplopia.

Operation in Cases of Ocular Palsy.-The planning of appropriate surgical treatment for a case of ocular palsy would be a simple matter if it were possible to predict precisely how many millimetres of retroplacement, or of resection of a muscle, were required in order to overcome any given angle of deviation. Although it is possible to lay down certain approximate figures giving the relationship of certain operations upon the ocular muscles to their effect on the angle of deviation, it is quite impossible to be dogmatic because there are so many variable factors to be considered.

The variable factors which must be taken into account in each case are:

(i) The size of the eyeball-the bigger the eyeball the greater the effect of any operation upon one of its muscles, and the smaller the eyeball the less the effect.

(ii) The degree of relative ex- or en-ophthalmos-the more protuberant the eye the greater the effect of any operation upon one of its muscles, and the less protuberant the eye the less the effect.

(iii) The strength of the muscle upon which the operation is performed-the stronger the muscle the greater the effect, the weaker the muscle the less the effect. 
(iv) The amount of contracture of the direct antagonist and of Tenon's capsule-only a small effect can be expected to result from resection of a muscle whose direct antagonist is in a state of gross contracture, unless at the same time the latter is adequately retroplaced and the contracted Tenon's capsule is freely divided.

(v) The amount of overaction of the contralateral synergist - an operation designed to weaken the overacting muscle will give a greater effect if the overaction is of gross degree.

(vi) The amount of paresis of the contralateral antagonist-an operation designed to strengthen this muscle will give a greater effect if the paresis is slight.

(vii) The age of the patient-the younger the patient the greater the effect of any ocular muscle operation.

(viii) The length of time the squint has been present-the longer the "squinting period" the less the effect of any ocular muscle operation.

(ix) The aetiological factor concerned in the causation of the ocular palsy-in paralytic strabismus due to a nerve lesion there is usually gross overaction of the contralateral synergist and an obvious contracture of the direct antagonist, therefore both these factors usually require surgical attention. On the other hand, in "paralytic" strabismus due to a relative defect of one or more of the ocular muscles caused by displacement of the eyeball due to orbital trauma, or in the case of a lesion of a muscle itself, there may be only slight overaction of the contralateral synergist and only slight contracture of the direct antagonist. Therefore, it is better to plan an operation to strengthen the primarily affected muscle.

(x) The variability of the angle of deviation-in paralytic strabismus in which the angle of deviation is relatively fixed and rigid, an operation upon any of the ocular muscles produces less effect than it does if the angle of deviation is variable.

It must also be borne in mind that it is a mistake to attempt to overcome a large angle of deviation by an operation upon one eye only, otherwise there is a grave risk of obtaining an asymmetrical result. For instance, a left convergent deviation of, say, $20^{\circ}$ due to paresis of the left lateral rectus might well be overcome by performing a retroplacement of the left medial rectus of $10 \mathrm{~mm}$., the result probably being orthophoria in the primary position; but such a procedure would be bad surgery, since it would almost certainly cause weakness of convergence and weakness of dextro-version of the left eye, resulting in horizontal diplopia for near objects, and on dextro-version. It is important to ensure that the two eyes move symmetrically and equally in all directions. In many cases, especially in those with a large angle of deviation, surgical treatment should be planned in a series of stages, with an interval of at least a week or 10 days between each successive stage. Accurate measurements of the deviation in the various directions of the gaze should be made between each stage so that the previously planned procedure can be reviewed and if necessary modified before subsequent operation.

It is important to realize that defects should in general be slightly undercorrected, rather than overcorrected. Patients are much more comfortable with an approach to orthophoria, than with an overcorrection which has the effect of producing a new paresis causing a deviation in the 
opposite direction. It is better to approach orthophoria in stages, than to overcorrect and then to be faced by a completely new problem.

Surgical Techn:que.- Some special features to notice include:

(1) Recessions and Resections of the rectus muscles are carried out by one of the recognized methods. In performing a recession, it is important to sever the muscle tendon cleanly from the sclera and to make the new insertion precisely parallel with the old. This is of special importance when dealing with the vertical recti, whose insertions are not parallel with the limbus.

(2) Marginal Myotomy has a useful place in the treatment of paretic strabismus of slight degree. It may be carried out under instillation cocaine anaesthesia, so that measurements of the deviation can be made before and during the course of the operation, using a sterilized Maddox rod and a spotlight. The spotlight is preferably held by an assistant so that it can be moved into various directions of the gaze. Surgical adjustment can be made step by step until the eyes are orthophoric in the desired direction. Orthophoria should be obtained when the eyes are looking down-this is more important than obtaining orthophoria in the primary position. The process of healing sometimes results in a slight return of the deviation but it is never more than 2 or 3 prism dioptres.

(3) The Superior Oblique Muscle can be approached between the trochlea and the insertion of the muscle, either trans-conjunctivally, or by the external route through the skin, preferably the former. A lengthening effect can be obtained by dividing the tendon lengthways, dividing the two halves at different levels and performing a tendon slide, by simple tenotomy, or by partial tenectomy. A shortening effect may be obtained by means of tenoplication orby resection. It should be borne in mind that, especially in the case of an adult, the torsional effect of operating upon the superior oblique muscle may be considerable, so that unless a torsional deviation, such that an operation upon the superior oblique is indicated, is present it may be wiser to operate upon the appropriate vertical rectus.

(4) The Inferior Ohlique Muscle can be approached either at its origin, or at or near its insertion. When it is exposed at its origin the muscle may be completely cut through, but this may have relatively little effect because the cut end may assume another attachment to the floor of the orbit. A much bigger effect is obtained by excising a piece of the muscle (partial myectomy). The exposure can be made through the skin or through the conjunctiva, the former method being on the whole more satisfactory. The approach to, or near to, the insertion of the muscle must be made through the conjunctiva between the lateral and inferior rectus muscles. The insertion may be retroplaced an accurately measured amount, as required. If it is desired to enhance the action of the inferior oblique, it may be plicated or resected.

AnAesthetic.- Although all these operations can, if required, be carried out under local anaesthesia, it is only in cases with small degrees of deviation, in which a marginal myotomy is planned and in which observations of the effect of the procedure during operation (by the use of the Maddox rod and spotlight) are required, that it is necessary to do so. The majority of these procedures are more conveniently carried out under general anaesthesia.

Post-Operative Treatment.-Either both eyes are left unpadded after operation, or else both are padded, depending upon the nature of the case. 
If both eyes are padded, the coverings are removed as soon as possible. In cases where a simple recession has been carried out, there is usually no need to pad the eyes at all, or at all events for not more than 24 hours, and in cases where a resection has been performed, either with or without a recession of the direct antagonist, the eyes need not be padded for more than two days. When the inferior oblique muscle has been approached through the skin, the eyes need never be padded. Orthoptic treatment should be resumed on the second or third day and maintained until the eyes have settled in their post-operative state.

\section{Surgical Operations upon Various Muscles}

\section{(1) Horizontally Acting Muscles}

Medial Rectus.-For reasons already stated it is undesirable to weaken this muscle excessively; hence it is wise to refrain from retroplacing this muscle more than $7 \mathrm{~mm}$. in an adult, and $5 \mathrm{~mm}$. in a child. The correction produced by a $5-\mathrm{mm}$. recession may vary from 7 to 10 prism dioptres.

Lateral-Rectus.-If this muscle is over-liberally retroplaced or tenotomized, a defect of abduction may result, but this is not likely to cause inconvenience because on full latero-version the nose acts as a natural occluder to the contralateral eye, so that a deviation of the visual axes which only occurs on full latero-version is not likely to give rise to diplopia.

A recession of the medial rectus of $5 \mathrm{~mm}$., combined with a resection of the ipsolateral lateral rectus of $5 \mathrm{~mm}$., gives an average correction of from 15 to 20 prism dioptres.

(2) Vertically Acting Muscles.-Since there is less elasticity in the vertical movements of the two eyes and since the vertical fusional reserve is considerably less than the horizontal fusional reserve, greater precision is required in operation upon the vertically acting muscles than upon the horizontally acting muscles. Furthermore, the field of binocular fixation is not limited in the upward and downward directions of the gaze by means of the nose.

It must also be remembered that the vertically acting muscles have a subsidiary action of torsion, and that, unless a torsional deviation exists which needs correction, an operation upon a vertically acting muscle to relieve a vertical deviation must be so planned that it does not produce a torsional one.

Vertical Recti.-In operating upon the vertical recti, it is important to remember that looking down is a far more important and useful movement for most people than is looking up. It is impossible to walk down steps, to eat one's food, drive a car, or land an aircraft without extensive use of the depressor muscles, therefore it is 
important to obtain more or less parallelism of the visual axes in depression of the eyeballs, because diplopia occurring on looking downwards is grossly inconvenient. Diplopia occurring only on looking upwards is for most people not unduly distressing.

It is desirable, however, to overcome diplopia in all directions of the gaze if possible.

In order to preserve symmetry of ocular movements it is important when dealing with paresis of one of the " dextro" vertical muscles (i.e. one of the vertically acting muscles the main action of which is exerted when the eyes are in dextro-version) to confine one's surgical attention for the most part to this group of muscles, otherwise an asymmetrical and incomitant result is likely to occur.

In general, $1 \mathrm{~mm}$. of retroplacement of one of the vertical recti overcomes a vertical deviation of about 4 to 5 prism dioptres when the eyes are in the primary position, and $1 \mathrm{~mm}$. of resection of one of the vertical recti overcomes a vertical deviation of about 3 prism dioptres when the eyes are in the primary position. This, of course, means that the effect will be greater when the eyes are looking in the direction of action of the muscle which has been operated upon, and less when looking in the opposite direction. This is an important practical point to bear in mind. For reasons already stated it is always desirable to aim at obtaining more or less orthophoria in depression of the eyeballs.

Recession or marginal myotomy gives a larger result when it is carried out on the inferior rectus than when it is performed on the superior rectus. This is probably due to Bell's phenomenon (elevation of the eyes on closure of the eyelids) which enhances the result of such surgical treatment on a depressor muscle by stretching it, and lessens the result of such treatment on an elevator muscle by keeping the muscle in a contracted state. From this it will be appreciated that padding the eyes after such operations may have either a beneficial or an adverse effect, depending on whether the surgical treatment has been insufficient or over-liberal and which muscle has been subjected to operation.

Obliques.-The simple and rather primitive operation of myectomy (or in some cases tenotomy) of the inferior oblique has sometimes been criticized as being an unscientific procedure, but the fact remains that in properly selected cases the result of such an operation is most satisfactory. Myectomy of the inferior oblique of an eye is indicated when there is an obvious updrift of that eye when the gaze is directed to the opposite side, i.e. if on dextro-version there is a gross updrift of the left eye, then a myectomy of the left inferior oblique should be performed. Such an updrift may be due to paresis of the ipsolateral superior oblique or of the contralateral superior rectus. 
A myectomy of the inferior oblique may also be indicated in the presence of excyclotropia or excyclophoria with or without an obvious overaction or contracture of the muscle.

The amount of effect obtained in terms of reduction of angle of deviation depends entirely upon the amount of overaction or contracture of the muscle.

We have never encountered an over-effect from this operation, provided that the eye in question showed an obvious updrift on contra-latero-version. The reduction of the angle of vertical deviation may be anything from 2 to 20 prism dioptres, and the reduction of excyclotorsion anything from $2^{\circ}$ to $12^{\circ}$.

Tenotomy of the superior oblique has not been frequently carried out in adults, because of the risk that excyclophoria or excyclotropia may result from weakening a muscle the action of which is intorsion. Conversely, tenoplication or resection of the superior oblique is likely to produce incyclotorsion. The first of these operations, however, may be indicated if overaction or contracture of the superior oblique is associated with incyclotorsion, and the second of these operations may be indicated if weakness of the superior oblique is associated with excyclotorsion.

The results of surgical treatment in the 219 cases under review are set out in Tables I to XXII. For the sake of brevity the only measurements of the angle of deviation recorded in the Tables are those taken in the primary position with a Maddox rod and a spotlight at $6 \mathrm{~m}$., the Maddox rod being placed in front of the affected eye, i.e. with the unaffected eye fixing. The following abbreviations are used throughout:

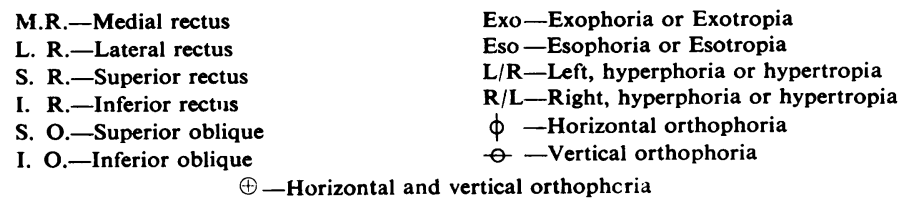

\section{Operations for Palsy of the lateral Rectus}

(Total cases 27, Tables I to IV)

In general, a case of palsy of the lateral rectus may be treated by:

(a) recession of the contralateral synergist (the contralateral medial rectus),

(b) recession of the direct anatagonist (the ipsolateral medial rectus,

(c) resection of the affected muscle,

(d) resection of the contralateral antagonist (the contralateral lateral rectus), or by a combination of any of these.

Where the deviation is small, a marginal myotomy may be substituted for a recession, and a tenoplication for a resection.

In a case of complete paralysis of the lateral rectus of acquired origin in which the patient is unable to abduct the afferted eye beyond the 
TABLE I

PALSY OF LATERAL RECTUS

Traumatic-due to 6 th cerebral nerve lesion

\begin{tabular}{|c|c|c|c|c|}
\hline \multirow{2}{*}{ Surgical Procedure } & \multirow{2}{*}{$\begin{array}{l}\text { No. of } \\
\text { Cases }\end{array}$} & \multirow{2}{*}{$\begin{array}{l}\text { Time since } \\
\text { Injury }\end{array}$} & \multicolumn{2}{|c|}{ Average Measurements } \\
\hline & & & $\begin{array}{l}\text { Pre-operative } \\
\text { (Esotropia) }\end{array}$ & $\begin{array}{l}\text { Post-operative } \\
\text { (Esophoria) }\end{array}$ \\
\hline$\left\{\begin{array}{c}\text { Recession ipsolateral M.R. } \ldots \\
\text { Resection and O'Connor's oper- } \\
\text { ation affected muscle }\end{array}\right.$ & 7 & 5 months & $38^{\triangle}$ & $2^{\Delta}$ \\
\hline Recession contralateral M.R. $\ldots$ & 2 & 5 months & $18 \cdot 5^{\Delta}$ & $4^{\triangle}$ \\
\hline$\left\{\begin{array}{l}\text { Recession ipsolateral M.R. } \\
\text { Resection contralateral L.R. } \ldots \\
\text { O'Connor's operation affected } \\
\text { muscle }\end{array}\right.$ & 1 & 23 months & $35^{\triangle}$ & $\oplus$ \\
\hline $\begin{array}{l}\text { Marginal myotomy ipsolateral } \\
\text { M.R. }\end{array}$ & 1 & 3 months & $4^{\triangle}$ & $2^{\Delta}$ \\
\hline Recession ipsolateral M.R. & 1 & 20 years & $22 \triangle$ & $6^{\Delta}$ \\
\hline $\begin{array}{l}\text { (1) }\left\{\begin{array}{c}\text { Recession ipsolateral M.R. } \\
\text { O'Connor's operation affected } \\
\text { muscle }\end{array}\right. \\
\text { (2) Recession contralateral M.R. }\end{array}$ & 1 & 1 year & $25^{\triangle}$ & $\theta$ \\
\hline $\begin{cases}\text { Recession ipsolateral M.R. } & \ldots \\
\text { Resection affected muscle } & \ldots\end{cases}$ & 2 & 18 months & $22^{\triangle}$ & $2 \Delta$ \\
\hline
\end{tabular}

mid-line, an O'Connor's (Hummelsheim's or Temple-Smith's) operation is indicated. The procedure, which involves strengthening the palsied lateral rectus by slips consisting of the outer or inner third of the superior and inferior rectus muscles respectively, gives some degree of abduction but will not usually abolish diplopia on the affected side altogether. This operation is usually combined with a recession of the ipsolateral antagonist and a resection of the affected muscle.

Congenital Palsy of the Lateral Rectus (Table III).-Certain cases are encountered in which one eye shows complete absence of abduction (dating from birth) and yet the visual axes are parallel in the primary position. In such cases, provided that there is approximately orthophoria in the primary position, operation is not indicated, for any operation which improves the power of abduction of the affected eye will automatically cause defective adduction and may result in a divergent squint. If, however, there is a fair degree of esophoria in the primary position (or perhaps even esotropia with a compensatory head turn to the side of the affected eye), then operation is indicated-usually a recession of the contralateral medial rectus and possibly a recession of the ipsolateral medial rectus: if the deviation is large a resection of the affected lateral rectus may also be performed. Where the deviation in the primary position is large and there is a marked compensatory head posture (head 
TABLE II

PALSY OF BOTH LATERAL RECTI

Traumatic-due to 6 th cerebral nerve lesions

\begin{tabular}{|c|c|c|c|c|}
\hline \multirow{2}{*}{ Surgical Procedure } & \multirow{2}{*}{$\begin{array}{l}\text { No. of } \\
\text { Cases }\end{array}$} & \multirow{2}{*}{$\begin{array}{c}\text { Time since } \\
\text { Injury }\end{array}$} & \multicolumn{2}{|c|}{ Average Measurements } \\
\hline & & & $\begin{array}{c}\text { Pre-operative } \\
\text { (Esotropia) }\end{array}$ & $\begin{array}{l}\text { Post-operative } \\
\text { (Esophoria) }\end{array}$ \\
\hline $\begin{array}{l}\text { (1) }\left\{\begin{array}{l}\text { Recession L.M.R. } \\
\text { Resection L.L.R. }\end{array}\right. \\
\text { (2) }\left\{\begin{array}{l}\text { Recession R.M.R. } \\
\text { Resection R.L.R. }\end{array}\right. \\
\text { (3) Re-recession L.M.R. }\end{array}$ & 1 & 4 months & $100^{\Delta}$ & $4^{\Delta}$ \\
\hline 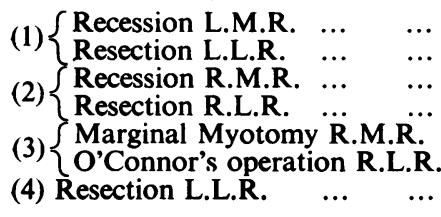 & 1 & 4 months & $51 \Delta$ & $8^{\Delta}$ \\
\hline
\end{tabular}

TABLE III

PALSY OF LATERAL RECTUS

Of congenital origin

\begin{tabular}{l|c|c|c}
\hline \multicolumn{1}{c|}{ Surgical Procedure } & $\begin{array}{c}\text { No. of } \\
\text { Cases }\end{array}$ & $\begin{array}{c}\text { Average Measurements } \\
\text { Pre-operative } \\
\text { (Esotropia) }\end{array}$ & $\begin{array}{c}\text { Post-operative } \\
\text { (Esophoria) }\end{array}$ \\
\hline Recession contralateral M.R. . . & 3 & $12^{\Delta}$ & $6 \Delta$ \\
\hline $\begin{array}{l}\text { Recession contralateral M.R. ... } \\
\text { Resection affected muscle } \ldots\end{array}$ & 1 & $15^{\Delta}$ & $7 \Delta$ \\
\hline $\begin{array}{l}\text { (1) Recession contralateral M.R. } \\
\text { (2) Recession ipsolateral M.R. }\end{array}$ & 1 & $35^{\Delta}$ & $1 \Delta$ \\
\hline $\begin{array}{l}\text { (1) Recession contralateral M.R. } \\
\text { (2) }\left\{\begin{array}{l}\text { Recession ipsolateral M.R. } \\
\text { Resection affected muscle ... }\end{array}\right.\end{array}$ & 1 & $50^{\Delta}$ & $13^{\Delta}$ \\
\hline
\end{tabular}

turn to the side of the lesion) O'Connor's operation is indicated. However, in very young children with such a lesion, a muscle transplant operation is in our opinion not indicated, as there is a risk of vertical imbalance resulting because of the instability of the binocular reflexes.

In cases of Duane's retraction syndrome, in which there is a peculiar fibrotic condition of the lateral and to some extent of the medial rectus, still greater care must be exercised and a muscle transplant operation is 
TABLE IV

PALSY OF LATERAL RECTUS

Of indeterminate pathology

\begin{tabular}{|c|c|c|c|c|}
\hline Surgical Procedure & $\begin{array}{l}\text { No. of } \\
\text { Cases }\end{array}$ & $\begin{array}{l}\text { Time since } \\
\text { Onset of } \\
\text { Strabismus }\end{array}$ & $\begin{array}{l}\text { Average M } \\
\text { Pre-operative } \\
\text { (Esotropia) }\end{array}$ & $\begin{array}{l}\text { Post-operative } \\
\text { (Esophoria) }\end{array}$ \\
\hline$\left\{\begin{array}{l}\text { Recession ipsolateral M.R. } \\
\text { Resection affected muscle }\end{array}\right.$ & 1 & 5 years & $30^{\triangle}$ & \\
\hline $\begin{array}{l}\text { (1) Recession contralateral M.R. } \\
\text { (2) Recession ipsolateral M.R... }\end{array}$ & 1 & 4 years & $25^{\triangle}$ & \\
\hline $\begin{array}{l}\text { (1) Recession contralateral M.R. } \\
\text { (2) Resection affected muscle ... }\end{array}$ & 1 & 7 years & $34^{\triangle}$ & 7 \\
\hline $\begin{array}{l}\text { (1) Recession ipsolateral M.R.... } \\
\text { (2) Myectomy ipsolateral I.O. }\end{array}$ & $1^{*}$ & 60 years & $\begin{array}{l}20^{\triangle} \\
\left(\mathrm{L} / \mathrm{R}^{\circ} \triangle\right)\end{array}$ & $\begin{array}{c}10^{\triangle} \\
\left(L / R 4^{\triangle}\right) \\
\text { symptom-free }\end{array}$ \\
\hline
\end{tabular}

* In this case there was also ipsolateral S.O. palsy

never indicated. A recession of the contralateral medial rectus is the operation of choice, sometimes to be followed by a small recession or marginal myotomy of the ipsolateral medial rectus. Some cases are complicated by a sursumvergent deviation of the affected eye, and may need in addition a myectomy of the ipsolateral inferior oblique.

\section{Operations for Palsy of the Medial Rectus}

\section{(Total cases 6, Tables $\mathrm{V}$ and VI)}

Paresis of the medial rectus may be treated by a tenotomy or recession of the lateral rectus of the opposite or of the same eye. If the deviation is large both muscles may be treated at the same operation. Our results show that a tenotomy of the lateral rectus of the opposite eye gave an average correction of 11 prism dioptres, while recession of the lateral

TABLE V

PALSY OF MEDIAL RECTUS

Due to orbital trauma

\begin{tabular}{lllll}
\hline \multicolumn{1}{c}{ Surgical Procedure } & $\begin{array}{c}\text { No. of } \\
\text { Cases }\end{array}$ & $\begin{array}{c}\text { Time since } \\
\text { Injury }\end{array}$ & $\begin{array}{c}\text { Average Measurements } \\
\text { Pre-operative } \\
\text { (Exotropia) }\end{array}$ & $\begin{array}{c}\text { Post-operative } \\
\text { (Exophoria) }\end{array}$ \\
\hline Partial tenotomy contralateral L.R. & 1 & 4 months & $4 \cdot 5 \Delta$ \\
\hline Recession contralateral L.R. & $\ldots$ & 1 & 6 months & $10 \Delta$ \\
\hline
\end{tabular}


TABLE VI

PALSY OF MEDIAL RECTUS

Of congenital origin

\begin{tabular}{ll|c|cc}
\hline \multicolumn{1}{c}{ Surgical Procedure } & $\begin{array}{c}\text { No. of } \\
\text { Cases }\end{array}$ & $\begin{array}{c}\text { Average Measurements } \\
\text { Pre-operative } \\
\text { (Exotropia) }\end{array}$ & $\begin{array}{c}\text { Post-operative } \\
\text { (Exophoria) }\end{array}$ \\
\hline Tenotomy contralateral L.R. & $\cdots$ & 2 & $20^{\Delta}$ & $5 \Delta$ \\
\hline Tenotomy both L.R. & $\cdots$ & $\cdots$ & 1 & $26^{\Delta}$ \\
\hline Recession contralateral L.R. & $\cdots$ & 1 & $6^{\Delta}$ & $7 \Delta$ \\
\hline
\end{tabular}

rectus of the opposite eye gave 7 prism dioptres of correction or approximately 2 prism dioptres for each millimetre of recession. In the one case, where both lateral rectus muscles were divided, the resulting correction was 19 prism dioptres.

\section{Operations for Palsy of the Superior Rectus \\ (Total cases 68, Tables VII to X)}

The usual surgical treatment for paresis of the superior rectus is a partial myectomy of the contralateral inferior oblique. In our series this gave an average correction of 7 prism dioptres, but the result achieved depends entirely upon the amount of overaction of the muscle. Thus the correction achieved may vary from 2 to 20 prism dioptres. Where the deviation due to the paresis is less, a myotomy of the inferior oblique muscle may be carried out. Recession of the inferior rectus muscle of the

TABLE VII

PALSY OF SUPERIOR RECTUS

Traumatic-due to nerve lesion

\begin{tabular}{|c|c|c|c|c|c|}
\hline \multirow{2}{*}{\multicolumn{2}{|c|}{ Surgical Procedure }} & \multirow{2}{*}{$\begin{array}{l}\text { No. of } \\
\text { Cases }\end{array}$} & \multirow{2}{*}{$\begin{array}{l}\text { Time since } \\
\text { Injury }\end{array}$} & \multicolumn{2}{|c|}{ Average Measurements } \\
\hline & & & & $\begin{array}{l}\text { Pre-operative } \\
\text { (Hypotropia) }\end{array}$ & $\begin{array}{l}\text { Post-operative } \\
\text { (Hypophoria) }\end{array}$ \\
\hline $\begin{array}{l}\text { (1) } \\
\text { (2) }\end{array}$ & $\begin{array}{l}\text { Myectomy contralateral I.O. } \\
\text { Marginal myotomy ipso- } \\
\text { lateral I.R. (controlled) }\end{array}$ & 2 & $2 \frac{1}{2}$ years & $14^{\Delta}$ & $3^{\Delta}$ \\
\hline \multicolumn{2}{|c|}{ Myectomy contralateral I.O. } & 2 & $4 \frac{1}{2}$ months & $4^{\Delta}$ & ( \\
\hline $\begin{array}{l}\text { (1) } \\
\text { (2) }\end{array}$ & $\begin{array}{l}\text { Myectomy contralateral I.O. } \\
\text { Marginal myotomy contra- } \\
\text { lateral S.R. (controlled) }\end{array}$ & 1 & $1 \frac{1}{2}$ years & $25^{\triangle}$ & $\odot$ \\
\hline
\end{tabular}


TABLE VIII

PALSY OF SUPERIOR RECTUS

Due to orbital trauma

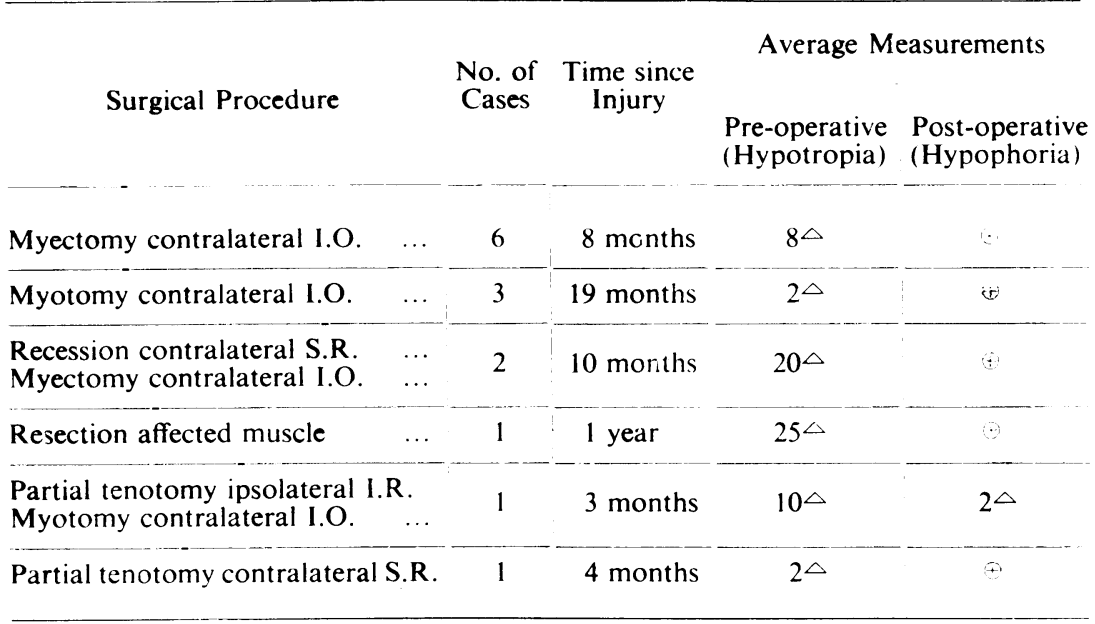

TABLE IX

PALSY OF SUPERIOR RECTUS

Due to exophthalmic ophthalmoplegia

\begin{tabular}{|c|c|c|c|}
\hline \multirow{2}{*}{ Surgical Procedure } & \multirow{2}{*}{$\begin{array}{l}\text { No of } \\
\text { Cases }\end{array}$} & \multicolumn{2}{|c|}{ Average Measurements } \\
\hline & & $\begin{array}{l}\text { Pre-operative } \\
\text { (Hypotropia) }\end{array}$ & $\begin{array}{l}\text { Post-operative } \\
\text { (Hypophoria) }\end{array}$ \\
\hline Resection affected muscls & 2 & $25 \triangle$ & $1^{\triangle}$ \\
\hline$\left\{\begin{array}{l}\text { Resection affected muscle } \\
\text { Recession ipsolateral I.R. }\end{array}\right.$ & 1 & $20 \triangle$ & 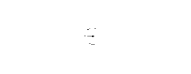 \\
\hline $\begin{cases}\text { Resection affected muscle } & \ldots \\
\text { Recession ipsolateral I.R. } & \ldots \\
\text { Myectomy contralateral I.O. } & \ldots\end{cases}$ & 1 & $37 \triangle$ & 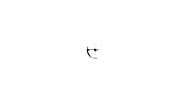 \\
\hline 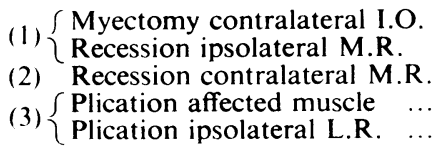 & $1^{*}$ & $\begin{array}{l}10^{\triangle} \\
(\text { and Eso 20॰ } \\
\text { and Excyclo. 10) }\end{array}$ & $\begin{array}{c}1^{\triangle} \\
\text { (no cyclc.) }\end{array}$ \\
\hline $\begin{array}{l}\text { (1) Recession ipsolateral I.R. } \\
\text { (2) Myectomy contralateral I.O. }\end{array}$ & 1 & $7 \triangle$ & $1<$ \\
\hline Myectomy contralateral I.O. & 1 & $20^{\triangle}$ & c \\
\hline $\begin{array}{l}\text { (1) Resection affected muscle } \\
\text { (2) Myectomy contralateral I.O. }\end{array}$ & 1 & $25^{\triangle}$ & $2^{\triangle}$ \\
\hline
\end{tabular}

\footnotetext{
* In this case there was also a palsy of the ipsolateral lateral rectus.
} 
same eye may be used, and this usually gives a correction in the primary position of approximately 4 or 5 prism dioptres for each millimetre of recession. Marginal myotomy of the inferior rectus muscle of the same eye is usually carried out with Maddox rod control at the time of operation, and can be varied in degree to give any desired effect up to about 5 prism dioptres. It is of course essential to carry out such a procedure under instillation cocaine anaesthesia only, since any injection of novocaine into the muscle or into the retrobulbar tissues will, by causing a temporary muscular paresis, jeopardize the effect of the observations.

In performing such an operation it is best to try to obtain orthophoria in depression of the eyeballs. If orthophoria is produced in the primary position there is likely to be a vertical deviation of the opposite type to that originally present, and a distressing diplopia on looking downwards may result.

TABLE X

PALSY OF THE SUPERIOR RECTUS

Of congenital origin

\begin{tabular}{|c|c|c|c|}
\hline \multirow{2}{*}{ Surgical Procedure } & \multirow{2}{*}{$\begin{array}{l}\text { No. of } \\
\text { Cases }\end{array}$} & \multicolumn{2}{|c|}{ Average Measurements } \\
\hline & & $\begin{array}{l}\text { Pre-operative } \\
\text { (Hypotropia) }\end{array}$ & $\begin{array}{l}\text { Post-operative } \\
\text { (Hypophoria) }\end{array}$ \\
\hline Myectomy contralateral I.O. $\quad \ldots$ & 29 & $8^{\triangle}$ & $3 \Delta$ \\
\hline $\begin{array}{l}\text { (1) Myectomy contralateral I.O. } \\
\text { (2) Recession ipsolateral I.R. }\end{array}$ & 6 & $17 \Delta$ & $3 \triangle$ \\
\hline Myotomy contralateral I.O. $\quad \ldots$ & 3 & $1 \cdot 5^{\Delta}$ & $\boxplus$ \\
\hline $\begin{array}{l}\text { (1) Myectomy contralateral I.O. } \\
\text { (2) Marginal myotomy contra- } \\
\text { lateral S.R. }\end{array}$ & 2 & $10 \cdot 5^{\Delta}$ & $3 \cdot 5^{\triangle}$ \\
\hline $\begin{array}{l}\text { (1) Myectomy contralateral I.O. } \\
\text { (2) Recession contralateral S.R.... }\end{array}$ & 2 & $25^{\triangle}$ & $4^{\triangle}$ \\
\hline $\begin{array}{l}\text { (1) Resection affected muscle } \\
\text { (2) Myectomy contralateral I.O. }\end{array}$ & 1 & $24^{\triangle}$ & $1 \Delta$ \\
\hline 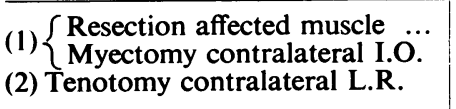 & 1 & $\begin{array}{c}33 \triangle \\
(\operatorname{Exo~} 35 \triangle)\end{array}$ & $\stackrel{\ominus}{\ominus}$ (Eso $3 \triangle)$ \\
\hline $\begin{array}{l}\text { (1) Myectomy contralateral I.O. } \\
\text { (2) Recession contralateral S.R. } \\
\text { (3) Tenotomy ipsolateral S.O. ... }\end{array}$ & 1 & $24^{\triangle}$ & $0.5^{\Delta}$ \\
\hline Recession ipsolateral I.R. & 1 & $12^{\triangle}$ & $\oplus$ \\
\hline
\end{tabular}


Marginal myotomy of the opposite superior rectus muscle may similarly be varied in degree to give any desired effect up to about 5 prism dioptres. Resection of the affected superior rectus muscle may be carried out and will give about 3 prism dioptres of correction per millimetre of resection. In certain cases combinations of operations are indicated, e.g. partial myectomy of the contralateral inferior oblique muscle combined with a marginal myotomy of the ipsolateral inferior rectus, or resection of the affected superior rectus muscle combined with myectomy of the opposite inferior oblique muscle. These different procedures can be carried out in sequence so that absolute correction is finally achieved.

Superior Rectus Palsy due to Exophthalmic Ophthalmoplegia (Table IX).In such cases good results are usually obtained by resection of the affected muscle; although in the more severe cases, in which there is an obvious contracture of the ipsolateral inferior rectus, a recession of this muscle must also be undertaken.

\section{Operations for Palsy of the Inferior Rectus}

\section{(Total cases 10, Tables XI and XII)}

In cases of paresis of the inferior rectus, if there is an obvious torsional defect (incyclotorsion) due to overaction of the contralateral superior oblique, the surgical treatment should include an operation designed to weaken this overacting muscle. The amount of incyclotorsion produced by an overacting superior oblique is, however, extremely variable. If no incyclotorsion is present, it is usually inadvisable to weaken the superior oblique to any extent since such a procedure may cause a discomforting excyclotorsion, although no doubt for reasons of adaptability such is less likely to inconvenience a child than an adult.

\section{TABLE XI}

\section{PALSY OF INFERIOR RECTUS}

Due to orbital trauma

\begin{tabular}{|c|c|c|c|c|c|}
\hline \multirow{2}{*}{\multicolumn{2}{|c|}{ Surgical Procedure }} & \multirow{2}{*}{$\begin{array}{l}\text { No. of } \\
\text { Cases }\end{array}$} & \multirow{2}{*}{$\begin{array}{l}\text { Time since } \\
\text { Injury }\end{array}$} & \multicolumn{2}{|c|}{ Average Measurements } \\
\hline & & & & $\begin{array}{l}\text { Pre-operative } \\
\text { (Hypertropia) }\end{array}$ & $\begin{array}{l}\text { Post-operative } \\
\text { (Hyperphoria) }\end{array}$ \\
\hline $\begin{array}{l}\text { (1) } \\
(2)\end{array}$ & $\begin{array}{l}\text { Recession ipsolateral S.R. ... } \\
\text { Partial tenotomy contra- } \\
\text { lateral S.O. }\end{array}$ & 1 & 13 months & $10^{\Delta}$ & 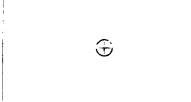 \\
\hline \multicolumn{2}{|c|}{ Recession contralateral I.R. } & 1 & 4 months & $19 \Delta$ & $8^{\Delta}$ \\
\hline $\begin{array}{l}\text { (1) } \\
\text { (2) }\end{array}$ & $\begin{array}{l}\text { Resection affected muscle ... } \\
\text { Recession contralateral M.R. }\end{array}$ & 1 & 4 months & (and Eso $8^{\Delta}$ ) & $\oplus$ \\
\hline
\end{tabular}


TABLE XII

PALSY OF INFERIOR RECTUS

Of congenital origin

\begin{tabular}{|c|c|c|c|}
\hline \multirow{2}{*}{ Surgical Procedure } & \multirow{2}{*}{$\begin{array}{l}\text { No. of } \\
\text { Cases }\end{array}$} & \multicolumn{2}{|c|}{ Average Measurements } \\
\hline & & $\begin{array}{l}\text { Pre-operative } \\
\text { (Hypertropia) }\end{array}$ & $\begin{array}{l}\text { Post-operative } \\
\text { (Hyperphoria) }\end{array}$ \\
\hline Advancement affected muscle $\ldots$ & 1 & $5 \triangle$ & $2 \cdot 5 \triangle$ \\
\hline Myectomy ipsolateral I.O. & 1 & $20^{\triangle}$ & $19 \Delta$ \\
\hline Recession contralateral I.R. & 1 & $19 \triangle$ & $8^{\Delta}$ \\
\hline $\begin{array}{l}\text { Myectomy ipsolateral I.O. . .. } \\
\text { Marginal myotomy contralateral } \\
\text { S.R. }\end{array}$ & 1 & $\left(\begin{array}{c}M^{\Delta} \text { Wing } \\
\left(\text { Exo } 10^{\triangle} \text { L/R } 7 \triangle\right.\end{array}\right)$ & 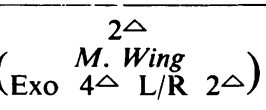 \\
\hline $\begin{array}{l}\text { (1) Resection affected muscle } \\
\text { (2) *Partial tenotomy contralateral } \\
\text { S.R. } \\
\text { (3) *Further tenotomy contra- } \\
\text { lateral S.R. } \\
\text { (4) Partial tenotomy contralateral } \\
\text { S.O. }\end{array}$ & 1 & $5 \Delta$ & $2 \Delta$ \\
\hline Recession ipsolateral S.R. & 1 & $8^{\triangle}$ & $1 \triangle$ \\
\hline $\begin{array}{l}\text { Recession ipsolateral S.R. } \\
\text { Resection affected muscle }\end{array}$ & 1 & $16^{\triangle}$ & $2^{\triangle}$ \\
\hline
\end{tabular}

* Necessary because (1) produced an over-effect

Operations for Palsy of the Superior Oblique

(Total cases 85 , Tables XIII to XVI)

Cases of paresis of the superior oblique muscle show contracture of the inferior oblique muscle of the same side with a resultant updrift of that

TABLE XIII

PALSY OF SUPERIOR OBLIQUE

Due to 4 th cerebral nerve lesion

\begin{tabular}{|c|c|c|c|c|}
\hline \multirow{2}{*}{ Surgical Procedure } & \multirow{2}{*}{$\begin{array}{l}\text { No. of } \\
\text { Cases }\end{array}$} & \multirow{2}{*}{$\begin{array}{l}\text { Time since } \\
\text { Injury }\end{array}$} & \multicolumn{2}{|c|}{ Average Measurements } \\
\hline & & & $\begin{array}{l}\text { Pre-operative } \\
\text { (Hypertropia) }\end{array}$ & $\begin{array}{l}\text { Post-operative } \\
\text { (Hyperphoria) }\end{array}$ \\
\hline $\begin{array}{l}\text { Marginal myotomy contralateral } \\
\text { I.R. }\end{array}$ & 9 & 22 months & $5^{\Delta}$ & $\frac{1}{2} \Delta$ \\
\hline Recession contralateral I.R. & 8 & $2 \frac{1}{2}$ years & $13^{\Delta}$ & $2^{\Delta}$ \\
\hline $\begin{array}{l}\text { Recession contralateral I.R. } \\
\text { Myectomy ipsolateral I.O. }\end{array}$ & 5 & 16 menths & $17^{\triangle}$ & $\frac{3}{4} \Delta$ \\
\hline Myectomy ipsolateral I.O. & 16 & 4 months & $6^{\Delta}$ & $\oplus$ \\
\hline
\end{tabular}


TABLE XIV

PALSY OF SUPERIOR OBLIQUE

Due to orbital trauma

Surgical Procedure $\quad \begin{aligned} & \text { No. of } \\ & \text { Cases }\end{aligned}$

Average Measurements

Pre-operative (Hypertropia)

Post-operative

Recession contralateral I.R.

(1) Myectomy ipsolateral I.O.

(2) Marginal myotomy contralateral I.R.

4

8 months

$6 \triangle$ $1 \triangle$

(1) Recession contralateral I.R. ..

(2) Marginal myotomy ipsolateral I.O.

25 months

$9 \triangle$

$0 \cdot 5^{\triangle}$

Myectomy ipsolateral I.O.

1

6 months

$5 \triangle$

$0 \cdot 5^{\triangle}$

2

7 months

$7 \triangle$

$1^{\triangle}$

(1) $\left\{\begin{array}{l}\text { Myectomy ipsolateral I.O.... } \\ \text { Recession contralateral I.R. }\end{array}\right.$

(2) Marginal myotomy ipsolateral S.R.

$1 \quad 19$ years

$21^{\triangle}$

$1 \triangle$

(3) Marginal myotomy contralateral I.R.

eye on full adduction. There is, therefore, a strong temptation to begin by carrying out a partial myectomy of the inferior oblique muscle (which in our series gave about 4.5 prism dioptres of correction, or a myotomy of the same muscle which gave about 3 prism dioptres of correction). In the absence of a specific indication for this operation, such as a gross torsional defect due to its contracture (excyclotorsion), or a gross updrift of the affected eye on adduction, it is usually wiser, if the vertical deviation in the primary position is large, to start by performing a recession of the inferior rectus of the opposite eye, which will give an average correction of

TABLE XV

PALSY OF SUPERIOR OBLIQUE

Of indeterminate pathology

\begin{tabular}{ccccc}
\hline Surgical Procedure & & $\begin{array}{c}\text { No. of } \\
\text { Cases }\end{array}$ & $\begin{array}{c}\text { Time since } \\
\text { Injury }\end{array}$ & $\begin{array}{c}\text { Average Measurements } \\
\text { Pre-operative Post-operative } \\
\text { (Hypertropia) }\end{array}$ \\
\hline Mycctomy ipsolateral I.O. & $\ldots$ & 1 & 6 months & $11.5 \triangle$ \\
\hline
\end{tabular}


TABLE XVI

PALSY OF SUPERIOR OBLIQUE

Of congenital origin

\begin{tabular}{|c|c|c|c|}
\hline \multirow{2}{*}{ Surgical Procedure } & \multirow{2}{*}{$\begin{array}{l}\text { No. of } \\
\text { Cases }\end{array}$} & \multicolumn{2}{|c|}{ Average Measurements } \\
\hline & & $\begin{array}{l}\text { Pre-operative } \\
\text { (Hypertropia) }\end{array}$ & $\begin{array}{l}\text { Post-operative } \\
\text { (Hyperphoria) }\end{array}$ \\
\hline Myectomy ipsolateral I.O. & 10 & $13^{\triangle}$ & $1 \cdot 5^{\Delta}$ \\
\hline $\begin{array}{l}\text { (1) Recession contralateral I.R. } \\
\text { (2) Myectomy ipsolateral I.O. ... }\end{array}$ & 8 & $18^{\Delta}$ & $2 \Delta$ \\
\hline $\begin{array}{l}\text { Marginal myotomy contralateral } \\
\text { I.R. }\end{array}$ & 5 & $6 \cdot 5^{\Delta}$ & $1 \frac{1}{2} \Delta$ \\
\hline Recession contralateral I.R. & 10 & $14^{\triangle}$ & $2^{\Delta}$ \\
\hline $\begin{array}{l}\text { (1) Myectomy ipsolateral I.O. ... } \\
\text { (2) Marginal myotomy contra- } \\
\text { lateral I.R. }\end{array}$ & 2 & $10^{\triangle}$ & $0.5^{\Delta}$ \\
\hline $\begin{array}{l}\text { (1) Myectomy ipsolateral I.O. ... } \\
\text { (2) Marginal myotomy ipso- } \\
\text { lateral S.R. } \\
\text { (3) Marginal myotomy contra- } \\
\text { lateral I.R. }\end{array}$ & 1 & $20^{\triangle}$ & $2 \Delta$ \\
\hline
\end{tabular}

4 or 5 prism dioptres for each millimetre of recession, and to perform subsequently a myectomy of the ipsolateral inferior oblique, if necessary, to correct a residual angle of deviation. This is especially true in cases of acquired palsy. In cases of congenital origin, the updrift is usually marked and an inferior oblique myectomy by itself gives, in most cases, an excellent result. A marginal myotomy of the opposite inferior rectus can give a correction of 4 to 7 prism dioptres. Marginal myotomy of the ipsolateral superior rectus can give a correction of up to 8 prism dioptres. Combined operations give a larger effect.

\section{Operations for Palsy of the INFERIOR ObliQue}

(Total cases 13, Tables XVII and VXIII)

The most satisfactory results are obtained in cases of paresis of the inferior oblique from a recession or marginal myotomy of the opposite superior rectus, the former procedure giving an average correction of 3 to 4 prism dioptres from each millimetre of retroplacement while the latter even if pushed to extremes cannot give a total correction of more than 4 or 5 prism dioptres. Recession of the opposite superior rectus, combined with a partial myectomy of the opposite inferior oblique can give about 12 prism dioptres of correction. 
TABLE XVII

PALSY OF INFERIOR OBLIQUE

Due to orbital trauma

\begin{tabular}{|c|c|c|c|c|}
\hline \multirow{2}{*}{ Surgical Procedure } & \multirow{2}{*}{$\begin{array}{l}\text { No. of } \\
\text { Cases }\end{array}$} & \multirow{2}{*}{$\begin{array}{l}\text { Time since } \\
\text { Injury }\end{array}$} & \multicolumn{2}{|c|}{ Average Measurements } \\
\hline & & & $\begin{array}{l}\text { Pre-operative } \\
\text { (Hypotropia) }\end{array}$ & $\begin{array}{l}\text { Post-operative } \\
\text { (Hypophoria) }\end{array}$ \\
\hline $\begin{array}{l}\text { Marginal myotomy contralateral } \\
\text { S.R. }\end{array}$ & 2 & $3 \frac{1}{2}$ months & $2 \triangle$ & $0 \cdot 25^{\triangle}$ \\
\hline $\begin{array}{l}\text { (1) Recession contralateral S.R. } \\
\text { (2) Partial myectomy contra- } \\
\text { lateral I.O. }\end{array}$ & 1 & 6 months & $20^{\triangle}$ & $1 \cdot 5^{\triangle}$ \\
\hline Recession contralateral S.R. & 1 & 3 months & $2^{\triangle}$ & j) \\
\hline $\begin{array}{l}\text { (1) Partial tenotomy contra- } \\
\text { lateral S.R. } \\
\text { (2) Partial myectomy contra- } \\
\text { lateral I.O. }\end{array}$ & 1 & 4 months & $14^{\triangle}$ & $2^{\Delta}$ \\
\hline
\end{tabular}

TABLE XVIII

PALSY OF THE INFERIOR OBLIQUE

Of congenital origin

\begin{tabular}{|c|c|c|c|c|}
\hline \multirow{2}{*}{\multicolumn{2}{|c|}{ Surgical Procedure }} & \multirow{2}{*}{$\begin{array}{l}\text { No. of } \\
\text { Cases }\end{array}$} & \multicolumn{2}{|c|}{ Average Measurements } \\
\hline & & & $\begin{array}{l}\text { Pre-operative } \\
\text { (Hypotropia) }\end{array}$ & $\begin{array}{l}\text { Post-operative } \\
\text { (Hypophoria) }\end{array}$ \\
\hline & ession contralateral S.R. & 6 & $14^{\triangle}$ & $4^{\triangle}$ \\
\hline $\begin{array}{l}\text { (1) } \\
\text { (2) }\end{array}$ & $\begin{array}{l}\text { Recession contralateral S.R. } \\
\text { Myectomy contralateral I.O. }\end{array}$ & 1 & $20^{\triangle}$ & $1 \cdot 5^{\triangle}$ \\
\hline $\begin{array}{l}(1) \\
(2) \\
(3)\end{array}$ & $\begin{array}{l}\text { Recession contralateral S.R. } \\
\text { Myectomy contralateral I.O. } \\
\text { Tenotomy ipsolateral S.O. . }\end{array}$ & 1 & $25^{\triangle}$ & $2^{\triangle}$ \\
\hline
\end{tabular}

\section{Operations for Palsy of More than One Extrinsic Ocular Muscle (Total cases 5, Table XIX)}

Operations for palsy of more than one of the extrinsic ocular muscles are planned on general principles. An example of a case of exophthalmic ophthalmoplegia in which the superior and lateral rectus of the same eye were both involved is mentioned in Table IX, and Table XIX refers to cases of orbital trauma in which two muscles were affected. The treatment of such cases presents no particular problem and the results may be as satisfactory as those in which only one muscle is involved. 
TABLE XIX

PALSY OF SEVERAL MUSCLES

Due to orbital trauma

\begin{tabular}{|c|c|c|c|c|c|c|}
\hline \multirow{2}{*}{$\begin{array}{l}\text { Muscles } \\
\text { Involved }\end{array}$} & \multirow{2}{*}{\multicolumn{2}{|c|}{ Surgical Procedure }} & \multirow{2}{*}{$\begin{array}{l}\text { No. of } \\
\text { Cases }\end{array}$} & \multirow{2}{*}{$\begin{array}{l}\text { Time } \\
\text { since } \\
\text { Injury }\end{array}$} & \multicolumn{2}{|c|}{ Measurements } \\
\hline & & & & & $\begin{array}{c}\text { Pre- } \\
\text { operative }\end{array}$ & $\begin{array}{c}\text { Post- } \\
\text { operative }\end{array}$ \\
\hline $\begin{array}{l}\text { R.I.R. } \\
\text { R.S.O. }\end{array}$ & $\begin{array}{l}(1) \\
(2) \\
(3)\end{array}$ & $\begin{array}{lll}\text { R.I.R. resection } & \ldots & \\
\text { R.I.O. myectomy } & \ldots & \ldots \\
\text { L.I.R. recession } & \ldots & . .\end{array}$ & 1 & $1 \frac{1}{2}$ years & $\begin{array}{l}\text { R/L } 36 \Delta \\
\text { Exo } 7 \Delta\end{array}$ & $\oplus$ \\
\hline $\begin{array}{l}\text { L.S.R. } \\
\text { L.S.O. }\end{array}$ & $\begin{array}{l}(1) \\
(2) \\
(3)\end{array}$ & $\begin{array}{l}\text { L.S.R. plication } \ldots \\
\text { L.I.R. marginal myotomy } . . \\
\text { R.I.O. myectomy } \ldots\end{array}$ & 1 & 4 months & $\begin{array}{c}\mathrm{R} / \mathrm{L} 16^{\Delta} \\
\text { Eso } 10^{\Delta} \\
\text { Excyclo. } \\
8^{\circ}\end{array}$ & $\mathrm{R} / \mathrm{L} \frac{1}{2} \Delta$ \\
\hline $\begin{array}{l}\text { L.I.R. } \\
\text { L.L.R. }\end{array}$ & (1) & $\begin{array}{ll}\text { L.I.R. resection } & \ldots \\
\text { R.M.R. recession } & \ldots\end{array}$ & 1 & 3 months & $\begin{array}{l}\text { L/R } 18^{\triangle} \\
\text { Eso } 8^{\triangle}\end{array}$ & $\begin{array}{l}\text { L/R } 1 \Delta \\
\text { Eso } 2^{\Delta}\end{array}$ \\
\hline $\begin{array}{l}\text { R.I.R. } \\
\text { R.M.R. }\end{array}$ & $\begin{array}{l}(1) \\
(2) \\
(3)\end{array}$ & $\begin{array}{ll}\text { R.I.R. resection } & \ldots \\
\text { R.M.R. resection } & \ldots \\
\text { L.L.R. tenotomy } & \ldots\end{array}$ & 1 & 6 years & $\begin{array}{l}\mathrm{R} / \mathrm{L} 15^{\Delta} \\
\text { Exo } 28^{\Delta}\end{array}$ & $\oplus$ \\
\hline $\begin{array}{l}\text { L.I.R. } \\
\text { L.L.R. }\end{array}$ & $\begin{array}{l}(1) \\
(2)\end{array}$ & $\begin{array}{l}\text { R.I.R. marginal myotomy.. } \\
\text { L..L.R. resection } \ldots\end{array}$ & 1 & 7 months & $\begin{array}{l}\text { L/R } 4^{\triangle} \\
\text { Eso } 4^{\triangle}\end{array}$ & $\mathrm{R} / \mathrm{L} \mathbf{1}^{\Delta}$ \\
\hline
\end{tabular}

\section{Operations for Partial 3rd Cerebral Nerve Palsy}

\section{(Total cases 3, Tables XX to XXII)}

Special mention must be made of cases of partial 3rd cerebral nerve palsy. We have only operated upon three cases, but all gave satisfactory results. Two cases were of traumatic origin, in one of them there was a complete 4th cerebral nerve palsy also. The third case was one of congenital origin.

The affected eye in cases of partial 3rd nerve palsy shows grossly defective elevation, defective depression, and defective adduction because of the involvement of both elevators (the superior rectus and the inferior oblique), one depressor (the inferior rectus), and the adductor (the medial rectus). There is also usually a slight degree of ptosis. The affected eye is deviated outwards and slightly downwards. In such a case it is quite obvious that no attempt to improve the power either of elevation or of depression in the affected eye by operating upon it will give a satisfactory result, since any improvement in the one movement will result in a greater defect in the other. Therefore, the best procedure is to weaken the corresponding movements of the unaffected eye. This essentially consists of a recession of the superior and of the lateral rectus. Although in such a case one cannot hope to restore binocular single vision in all directions 
TABLE XX

PALSY OF LEFT 3rd CEREBRAL NERVE

Traumatic due to nerve lesion

\begin{tabular}{|c|c|c|c|}
\hline \multirow{2}{*}{ Surgical Procedure } & \multirow{2}{*}{$\begin{array}{c}\text { Time since } \\
\text { Injury }\end{array}$} & \multicolumn{2}{|c|}{ Measurements } \\
\hline & & Pre-operative & Post-operative \\
\hline $\begin{array}{l}\text { Recession contralateral superior } \\
\text { rectus } 7 \mathrm{~mm} \text {. } \\
\text { Recession contralateral lateral rectus } \\
7 \mathrm{~mm} \text {. }\end{array}$ & $1 \frac{1}{2}$ years & $\begin{array}{ll}\mathrm{R} / \mathrm{L} & 20^{\circ} \\
\mathrm{Exo} & 12^{\circ}\end{array}$ & \\
\hline $\begin{array}{l}\text { Marginal myotomy contralateral } \\
\text { S.R. } \\
\text { Myectomy contralateral I.O. } \quad \ldots\end{array}$ & $1 \frac{1}{2}$ years & $\begin{array}{l}\mathrm{R} / \mathrm{L} 25^{\triangle} \\
\text { Exo } 4 \triangle\end{array}$ & \\
\hline
\end{tabular}

TABLE XXI

PALSY OF RIGHT 3rd CEREBRAL NERVE AND

RIGHT 4th CEREBRAL NERVE

Traumatic-due to nerve lesions

\begin{tabular}{|c|c|c|c|c|}
\hline \multirow{2}{*}{\multicolumn{2}{|c|}{ Surgical Procedure }} & \multirow{2}{*}{$\begin{array}{c}\text { Time since } \\
\text { Injury }\end{array}$} & \multicolumn{2}{|c|}{ Measurements } \\
\hline & & & Pre-operative & Post-operative \\
\hline (2) \{ & $\begin{array}{l}\text { Recession contralateral inferior } \\
\text { rectus } \\
\text { Recession contralateral lateral } \\
\text { rectus } \\
\text { Myectomy ipsolateral inferior } \\
\text { oblique } \\
\text { Myectomy contralateral inferior } \\
\text { oblique (to overcome ex- } \\
\text { cyclotrosion } 12 \text { ) } \\
\text { Re-recession contralateral } \\
\text { lateral rectus }\end{array}$ & $1 \frac{1}{2}$ years & $\begin{array}{ll}\mathrm{R} L \mathrm{~L} & 12 \\
\mathrm{ExO} & 12\end{array}$ & $\begin{array}{l}\mathrm{R} \text { L 2 } \\
\text { Excyclo. } 2\end{array}$ \\
\hline
\end{tabular}

In this case the affected (right) eye (in which there was also an ipsolateral 4th cerebral nerve palsy) showed a much greater defect of depression than of elevation. In consequence in the primary position the vertical deviation was one of right hypertropia.

of the gaze, one can, at all events, restore a reasonably large area of binocular single vision in the central part of the binocular field.

It should be explained that the measurements of deviation refer in all cases to the primary position, and are made with the patient's head in the erect position (or in the case of a patient showing congenital 
TABLE XXII

PALSY OF RIGHT 3rd CEREBRAL NERVE

Of congenital origin

\begin{tabular}{|c|c|c|c|c|}
\hline \multirow[b]{2}{*}{ Surgical Procedure } & & & \multicolumn{2}{|c|}{ Measurements } \\
\hline & & & Pre-operative & Post-operative \\
\hline 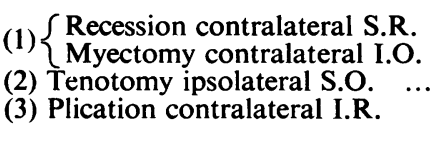 & $\begin{array}{l}\cdots \\
\cdots \\
\cdots\end{array}$ & \begin{tabular}{l|l}
$\cdots$ & \\
$\cdots$ & \\
$\cdots$ & \\
$\cdots$ &
\end{tabular} & $\mathrm{L} / \mathrm{R} \mathrm{14} \triangle{ }^{\Delta}$ & $\oplus$ \\
\hline
\end{tabular}

ocular palsy with a compensatory head posture, as erect as the secondary anatomical changes in the musculo-skeletal system permit). The Maddox rod is used with a spotlight situated at a distance of $6 \mathrm{~m}$. In the lateral directions of the gaze in the case of palsy of the horizontally acting muscles, and in the vertical and lateral directions of the gaze in the case of the vertically acting muscles, there may be a considerable increase or decrease in the angle of deviation. This may be affected in such a way as to produce the opposite type o deviation if too much is attempted at one operation. It is desirable to bear this in mind and try to produce as symmetrical a result as possible, so that parallelism of the visual axes shall be obtained if possible in all directions of the binocular gaze, or at all events over a wide central area of the binocular field, including the lower part.

\section{Discussion}

The reports of the case results show that many combinations of surgical procedure may be required in the treatment of cases of paralytic strabismus. Further, the results of similar surgical procedures are by no means uniform. These facts illustrate the essential point which must be remembered that the fullest consideration must be given to the treatment of each individual case in order to plan the surgical sortie, or sorties, if successful results are to be obtained. It is recognized in the surgical treatment of the extrinsic ocular muscles that the results of a particular surgical procedure are never accurate and definite. The figures which we record as average results of the various operations can be regarded as no more than a general guide to the correction to be obtained in any particular case, and experience will teach how they can be applied. Each case must be individually assessed before operation and between the various stages of operation. 
The opinion still persists among many ophthalmologists that little can be done for cases of paralytic strabismus, and that it is not worth while embarking on surgical treatment for this condition. It is our considered opinion, however, that the majority of patients suffering from ocular palsy can be helped materially, and indeed many of them can be restored to a state of orthophoria in the primary position, and to binocularity within most of the visual field.

We are indebted to Mr. E. R. Alexander for preparing the diagrams, to Miss Jean Anderson for help in compiling the tables, and to Messrs. Baillière, Tindall, and Cox for permission to use the block in Fig. 10.

\section{REFERENCES}

AdLer, F. H. (1948). Amer. J. Ophthal., 31, 387.

ANDERSON, J. R. (1947). British Journal of Ophthalmology, Monograph Suppl. XII.

Bielschowsky, A. (1935). Arch. Ophthal., Chicago, 13, 33, 751. (1938). Ibid., 20, 175 .

(1940). "Lectures on Motor Anomalies". Dartmouth College Publications, Hanover, New Hampshire.

Burian, H. M. (1950). Amer. J. Ophthal., 33, 380. (1950). Ibid., 33, 577.

Chavasse, F. B. (1939). "Worth's Squint", 7th ed. Baillière, Tindall and Cox, London.

Cross, A. G. (1944). M. D. Thesis, Cambridge University. (1945). Trans, ophthal. Soc. U.K., 65, 20.

Duane, A. (1916). Arch. Ophthal., N.Y., 45, 33.

Dunnington, J. H. (1948). Amer. J. Ophthal., 31, 1404

EPSTEIN, G. J. (1947). Arch. Ophthal., Chicago, 37, 369.

FecosI, M. (1948). " Palsies of Extrinsic Ocular Muscles: Symptomatology and Diagnosis". Edit. Abuzzini, Rome.

Franceschetti, A., and Blum, J. D. (1950). Ophthalmologica, Basel, 120, 93.

KRIMSKY, E. (1948). " The Management of Binocular Imbalance ". Kimpton, London.

LANDOLT, E., and LANDOLT, M. (1913). "Defective Ocular Movements and their Diagnosis". Oxford University Press, London.

LLOYD, I. (1949). British Journal of Ophthalmology, 33, 291.

Loutfallah, M. (1949). Ann. Oculist., Paris, 182, 81.

LYLE, T. K. (1950). "Worth and Chavasse's Squint", 8th ed. Baillière, Tindall and Cox, London.

(1941). Trans. ophthal. Soc. U.K., 61, 189.

(1941). Trans. ophthal. Soc.

(1949). Trans. ophthal. Soc. Aust., 9, 76.

and JACKSON, S. (1949). "Practical Orthoptics in the Treatment of Squint", 3rd ed. Lewis, London.

MaddoX, E. E. (1907). "Tests and Studies of the Ocular Muscles”, 2nd ed. Keystone Publishing Co., Philadelphia.

McGillivray, J. (1948). Canad. med. Ass. J., 58, 361.

McGuire, W. P. (1948). Amer. J. Ophthal., 31, 65.

MCLeAN, J. M. (1948). Trans. Amer. ophthal. Soc., 46, 633.

MeesmanN, A. (1948). Ber. dtsch. ophthal. Ges. Heidelberg, 54, 256.

NEELY, J. C. (1947). British Journal of Ophthalmology, 31, 581.

PAYNE, B. F. (1948). Amer. J. Ophthal., 31, 1217.

PoseY, W. C. (1916). Arch. Ophthal., N.Y., 45, 137.

Soriano, F. J., and Garcia Nocito, P. F. (1948). "Diagnostico de las paralisis oculares". El Atenso, Buenos Aires.

Zavalia, A. U. (1948). Arch. oftal. B. Aires, 23, 172. 